
polymer derivatives with high oxygen evolution performance. Advanced Energy Materials, 2002228 (13 pp.). https://doi.org/10.1002/aenm.202002228

\title{
Understanding and optimizing ultra-thin coordination polymer derivatives with high oxygen evolution performance
}

Yonggui Zhao,,$*$ Wenchao Wan, $\stackrel{+}{*}$ Y Chen, Rolf Erni, C. A. Triana, Jingguo Li, Christos K. Mavrokefalos, Ying Zhou and Greta R. Patzke*

Y. G. Zhao, W. C. Wan, Dr. C. A. Triana, J. G. Li, Dr. C. K. Mavrokefalos, and Prof. G. R. Patzke

Department of Chemistry, University of Zurich, Winterthurerstrasse 190, CH-8057 Zurich, Switzerland

E-mail: greta.patzke@,chem.uzh.ch

Y. Chen and Prof. Y. Zhou

State Key Laboratory of Oil and Gas Reservoir and Exploitation and The Center of New Energy Materials and Technology, School of New Energy and Materials, Southwest Petroleum University, Chengdu 610500, China

Dr. R. Erni

Electron Microscopy Center, Empa, Swiss Federal Laboratories for Materials Science and Technology, Überlandstrasse 129, CH-8600 Dübendorf, Switzerland

Keywords: electrocatalysis, nanosheets, disorder, coordination polymers, oxygen evolution reaction

\begin{abstract}
Engineering low-crystalline and ultra-thin nanostructures into coordination polymer assemblies is a promising strategy to design efficient electrocatalysts for energy conversion and storage. However, the rational utilization of coordination polymers (CPs) or their derivatives as electrocatalysts has been hindered by a lack of insight into their underlying catalytic mechanisms. Herein, we present a convenient approach where a series of $\mathrm{Ni}_{10-\mathrm{x}} \mathrm{Fe}_{\mathrm{x}}-\mathrm{CPs}(0 \leq \mathrm{x} \leq 5)$ is first synthesized, followed by the introduction of abundant structural deficiencies using a facile reductive method $\left(\mathrm{R}-\mathrm{Ni}_{10-\mathrm{x}} \mathrm{Fe}_{\mathrm{x}}-\mathrm{CPs}\right)$. The representative low-crystalline $\mathrm{R}-\mathrm{Ni}_{8} \mathrm{Fe}_{2}-\mathrm{CPs}$, referred to as $\mathrm{R}-\mathrm{NiFe}-\mathrm{CPs}$, with a thickness of sub-2 nm display promising oxygen evolution reaction (OER) performance with a very low overpotential of $225 \mathrm{mV}$ at $10 \mathrm{~mA} / \mathrm{cm}^{2}$ and high long-term durability over $120 \mathrm{~h}$. Comprehensive investigations including XAS, DFT, and mass
\end{abstract}


diffusion theory revealed strong synergistic effects of structural deficiencies on the OER activity. A super-Nernstian $\mathrm{pH}$-dependence of $85.15 \mathrm{mV} \mathrm{pH}^{-1}$ suggested that the catalytic OER mechanism of R-NiFe-CPs processed via a decoupled proton-electron transfer (PT/ET) pathway, which leads to notably higher OER activity compared to the concerted coupled proton-electron transfer (PCET) pathway. We showcase new insights into the catalytic reaction mechanisms of CP-related materials, opening up new approaches to expedite the design of efficient electrocatalysts.

\section{Introduction}

The development of low-cost and efficient electrocatalysts is of great importance to resolve the interconnected issues of fossil fuel shortage and climate change. ${ }^{[1]}$ Noble metal-based materials (e.g. Pt and its alloys) have been well investigated and are among the most promising electrocatalysts for water splitting to generate clean hydrogen. ${ }^{[2-3]}$ However, Pt group-based catalysts are still constrained by their scarcity and high cost for scalable and commercial electrocatalysis. Hence, the development of noble-metal-free catalysts with comparable catalytic activity and robust durability is an urgent task to realize technical applications of water electrolysis. ${ }^{[4-5]}$

Coordination polymer assemblies (CPAs), which are composed of a metal center linked to organic or inorganic ligands combine tunable porous structures, well-dispersed metal sites, high surface areas, and good chemical stability. This renders them excellent materials for drug delivery, ${ }^{[6]}$ gas storage and separation, ${ }^{[7]}$ batteries, ${ }^{[8-9]}$ and catalysis. ${ }^{[10-13]}$ Thanks to their unique structural properties, transition metal-based CPAs keep attracting broad interest in the field of heterogeneous electrocatalysts. ${ }^{[9-14]}$ However, their intrinsic poor conductivity, low mass permeability, and confined active metal centers need to be systematically improved for their application as efficient electrocatalysts. Moreover, instability issues of the ligands such as self- 
oxidation or degradation at high oxidation potentials need to be resolved for directly using CPAs as long-term electrocatalysts. ${ }^{[14-17]}$ Several strategies, e.g. morphological modulation, electronic tuning, and surface modification, have been confirmed as promising approaches to improve the electrocatalytic performance of CPAs and CPs. ${ }^{[14,16-21]}$ For example, ultra-thin NiCo bimetallic CPA nanosheets with enhanced OER activity compared to bulk NiCo bimetallic CPAs, were synthesized through an ultrasonication exfoliation method. ${ }^{[14]}$ Zhang et al. ${ }^{[16]}$ demonstrated that monolayered heterogenous nanosheets of hybrid $\mathrm{CoFeO}_{\mathrm{x}} / \mathrm{CPAs}$ were promising OER electrocatalysts. Some of us recently ${ }^{[20]}$ proposed that the high and durable electrocatalytic activity of an new one-dimensional cobalt coordination polymer $\left(\mathrm{Co}-\mathrm{dppeO} \mathrm{O}_{2}\right)$ is due to its highly disordered structure, giving rise to exceptional resilience. Further theoretical calculations and in-situ characterizations proved that the key architecture behind the high OER activity was arising from the $\left\{\mathrm{H}_{2} \mathrm{O}-\mathrm{Co}_{2}(\mathrm{OH})_{2}-\mathrm{OH}_{2}\right\}$ edge-site motifs. This study demonstrated the high potential of low-cost and disordered CPs-based catalysts for a sustainable economy. Moreover, CPA- or CP-derived compounds have recently emerged as new competitive candidates compared to many of the state-of-the-art transition metal-based electrocatalysts. ${ }^{[19-}$ ${ }^{24]}$ Despite these tremendous achievements on CPAs and CPs, their straightforward construction as efficient transition metal-based electrocatalysts still remains a challenge.

Herein, we rationally constructed a series of $\mathrm{Ni}_{10-\mathrm{x}} \mathrm{Fe}_{\mathrm{x}}-\mathrm{CPs}$ based on a modified roomtemperature coprecipitation method, ${ }^{[25]}$ followed by a reduction protocol for achieving ultrathin reduced $\mathrm{R}-\mathrm{Ni}_{10-\mathrm{x}} \mathrm{Fe}_{\mathrm{x}}-\mathrm{CP}$ nanosheets with tunable and significant degrees of structural deficiencies (Figure 1a). The processes of coordination polymer growth and the introduction of structural deficiencies were systematically investigated with PXRD, FTIR, Raman, and X-ray absorption 
a

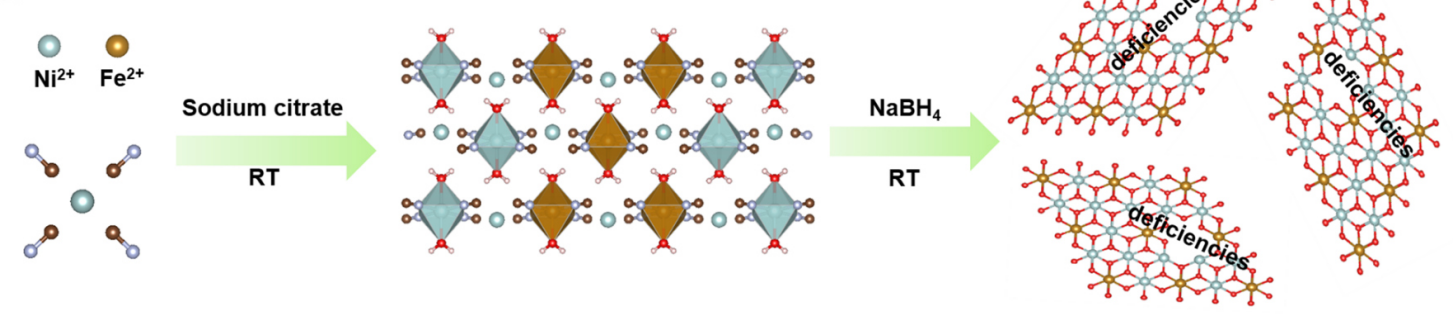

Cyanonickelate

Layered NiFe-CP nanosheets

Monolayered R-NiFe-CP nanosheets with deficiencies
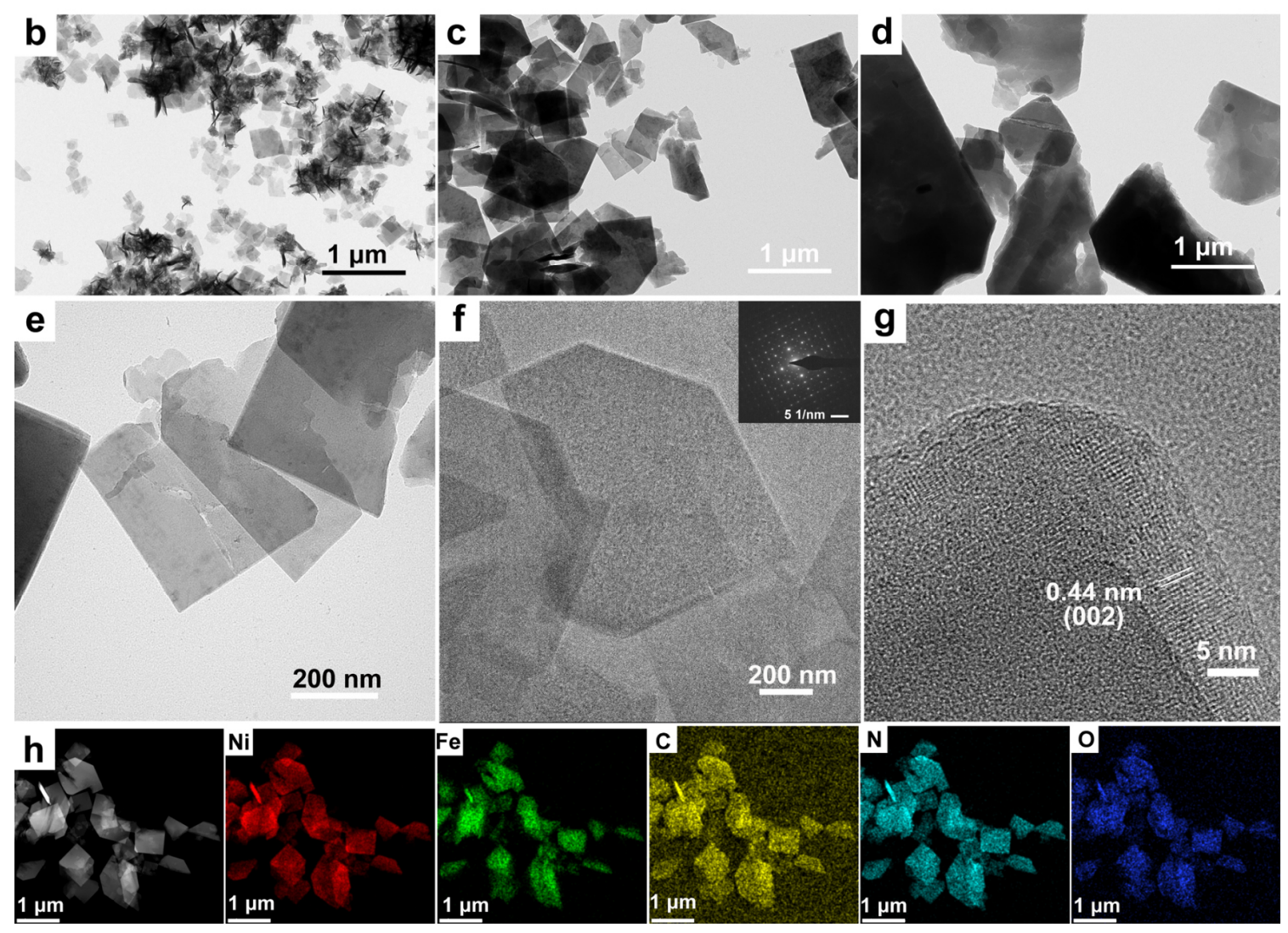

Figure 1. (a) Schematic diagram of the synthesis process. (b) TEM images of Ni-CP nanosheets. (c, e) TEM images of $\mathrm{Ni}_{8} \mathrm{Fe}_{2}-\mathrm{CP}(\mathrm{NiFe}-\mathrm{CP})$ nanosheets. (d) TEM images of $\mathrm{Ni}_{5} \mathrm{Fe}_{5}-\mathrm{CP}$ nanosheets. (f, g) High-resolution transmission electron microscopy (HR-TEM) images of NiFe-CP nanosheets, the inset in (f) shows the corresponding selected area electron diffraction (SAED) pattern. (h) High-angle annular dark field-scanning transmission electron microscopy (HAADF-STEM) images and scanning transmission electron microscopyenergy dispersive X-ray spectroscopy (STEM-EDX) elemental maps of NiFe-CP nanosheets (colors: red $=\mathrm{Ni}$, green $=\mathrm{Fe}$, yellow $=\mathrm{C}$, cyan $=\mathrm{N}$, blue $=\mathrm{O}$ ) . 
spectroscopy (XAS) analyses. We found that the morphologies, nanostructures, and structural deficiencies of the resulting products can be simultaneously tuned by controlling the initial atomic ratio of $\mathrm{Ni} / \mathrm{Fe}$ and the concentration of $\mathrm{NaBH}_{4}$ as reducing agent. When employed as OER electrocatalysts, low-crystalline and ultra-thin R-NiFe-CPs afforded an ultra-low overpotential of $225 \mathrm{mV}$ at a current density of $10 \mathrm{~mA} / \mathrm{cm}^{2}$, a small Tafel slope value of 27.78 $\mathrm{mV} / \mathrm{dec}$, and robust electrochemical durability for $120 \mathrm{~h}$ without any performance decline. This efficient OER performance surpasses the state-of-the-art $\mathrm{RuO}_{2}$ and many prominent NiFebased electrocatalysts. We furthermore comprehensively investigate the catalytic mechanism with a combination of XAS techniques and density functional theory (DFT) calculations.

\section{Results and discussion}

\subsection{Synthesis of $\mathrm{Ni}_{10-\mathrm{x}} \mathrm{Fe}_{\mathrm{x}}-\mathrm{CP}$ nanosheets}

The $\mathrm{Ni}_{10-\mathrm{x}} \mathrm{Fe}_{\mathrm{x}}-\mathrm{CP}(0 \leq \mathrm{x} \leq 5)$ samples were prepared through a coprecipitation method (see details in the $\mathrm{SI}$ ) and phase purity of as-prepared $\mathrm{Ni}_{10-\mathrm{x}} \mathrm{Fe}_{\mathrm{x}}-\mathrm{CP}$ products was first confirmed with PXRD patterns (Figure S1). All of the diffraction patterns of Ni-CPs were assigned to an orthorhombic system, which matched well with that of simulated Ni-CPs with a laminar structure (ICSD No. 251885, $\mathrm{Ni}\left(\mathrm{H}_{2} \mathrm{O}\right)_{2}\left[\mathrm{Ni}(\mathrm{CN})_{4}\right] \cdot \mathrm{xH}_{2} \mathrm{O}$, S.G. Imma). ${ }^{[25,26]}$ Two different $\mathrm{Ni}$ sites are present in the crystal structure (Figure S1a), of which the octahedral site is coordinated by $4 \mathrm{~N}$ and $2 \mathrm{O}$ atoms, and the square-planar site is coordinated by $4 \mathrm{C}$ atoms. When increasing the Fe content, the PXRD patterns of the $\mathrm{Ni}_{10-\mathrm{x}} \mathrm{Fe}_{\mathrm{X}}-\mathrm{CPs}$ (Figure $\mathrm{S} 1 \mathrm{~b}, \mathrm{c}$ ) still agree with the initial host crystal structure, while exhibiting a peak shift to lower angles at around $2 \theta \approx 9.3^{\circ}$, suggesting the successful incorporation of Fe into the Ni-CP lattice. ${ }^{[27]}$ The structural functional groups and coordination environments of the $\mathrm{Ni}_{10-\mathrm{x}} \mathrm{Fe}_{\mathrm{x}}-\mathrm{CP}$ samples were further corroborated by FTIR and Raman spectroscopy (Figures S2 and S3). The obtained results demonstrated that

the vibrational signature of $\mathrm{Ni}_{10-\mathrm{x}} \mathrm{Fe}_{\mathrm{x}}-\mathrm{CP}$ samples did not significantly change, while some main 
vibration modes (e.g. M-NC-Ni) displayed a shift to lower wavelengths due to the substitution of Ni by Fe. The corresponding field-emission scanning electron microscopy (FESEM, Figure S4) and transmission electron microscopy images (TEM, Figures 1b-e) showed the typical twodimensional nanosheet morphologies of the as-prepared products. As shown in Figures 1b-e and Figure S4, the introduction of Fe played a key role in the morphological evolution of NiCPs. After the initial atomic ratio of $\mathrm{Ni} / \mathrm{Fe}$ was increased to 1:1, the $2 \mathrm{D}$ nanosheet morphologies were well preserved, however, the numbers of layers and lateral size of $\mathrm{Ni}_{5} \mathrm{Fe}_{5}-\mathrm{CPs}$ were increased compared to the pristine Ni-CPs (Figures 1b,d and Figure S4). This morphology change is probably due to the presence of $\mathrm{Fe}^{3+}$ in the products, which possesses much stronger electronic affinity to the ligands compared with that of $\mathrm{Ni}^{2+}$ and $\mathrm{Fe}^{2+}$, giving rise to the anisotropic crystal growth with larger crystal size. ${ }^{[28-30]}$ Meanwhile, energy dispersive X-ray (EDX) and inductively coupled plasma mass spectrometry (ICP-MS) were employed to analyze the atomic ratio of $\mathrm{Ni} / \mathrm{Fe}$ in the $\mathrm{Ni}_{10-\mathrm{x}} \mathrm{Fe}_{\mathrm{x}}$-CPs (Figure $\mathrm{S} 5$ and Table S5). It was observed that the atomic ratio of $\mathrm{Ni} / \mathrm{Fe}$ in the $\mathrm{Ni}_{8} \mathrm{Fe}_{2}-\mathrm{CPs}$ (which are referred to representatively in the following as NiFe-CPs) obtained from EDX (3.18:1) and ICP-MS (3.21:1) measurements was quite close, albeit not identical with the ratio within the starting materials (4:1). The lower atomic ratio of $\mathrm{Ni} / \mathrm{Fe}$ of the as-synthesized $\mathrm{CPs}$ most likely results from the fact that the nucleation ability of $\mathrm{Ni}$ ions is weaker than that of $\mathrm{Fe}$ ions, so that a fraction of the $\mathrm{Ni}$ ions was most likely not involved in the nucleation process but remained in the solution and was removed by purification afterwards (Table S1). ${ }^{[17]}$ Selected area electron diffraction (SAED) patterns and high-resolution transmission electron microscopy (HR-TEM) images were recorded for further phase analyses of the $\mathrm{Ni}_{8} \mathrm{Fe}_{2}-\mathrm{CPs}$ (Figures 1f, g). The diffraction spots in the SAED patterns exhibit similar features as can be expected from the corresponding crystal structure (Figure S1). Each of these nanosheets clearly displays crystalline features as evident from the SAED patterns. The HR-TEM image shows a lattice spacing of $0.44 \mathrm{~nm}$, which is assigned to the (002) plane of the NiFe-CPs. Moreover, scanning transmission electron microscopy-energy dispersive X- 
ray spectroscopy (STEM-EDX) and FESEM-EDX elemental mapping images (Figure $1 \mathrm{~h}$ and Figure $\mathrm{S} 6$ ) reveal the homogenous distribution of $\mathrm{Ni}, \mathrm{Fe}, \mathrm{C}, \mathrm{N}$, and $\mathrm{O}$ over the selected area, indicating the successful formation of homogenous $\mathrm{Ni}_{10-\mathrm{x}} \mathrm{Fe}_{\mathrm{x}}-\mathrm{CP}$ nanosheets.
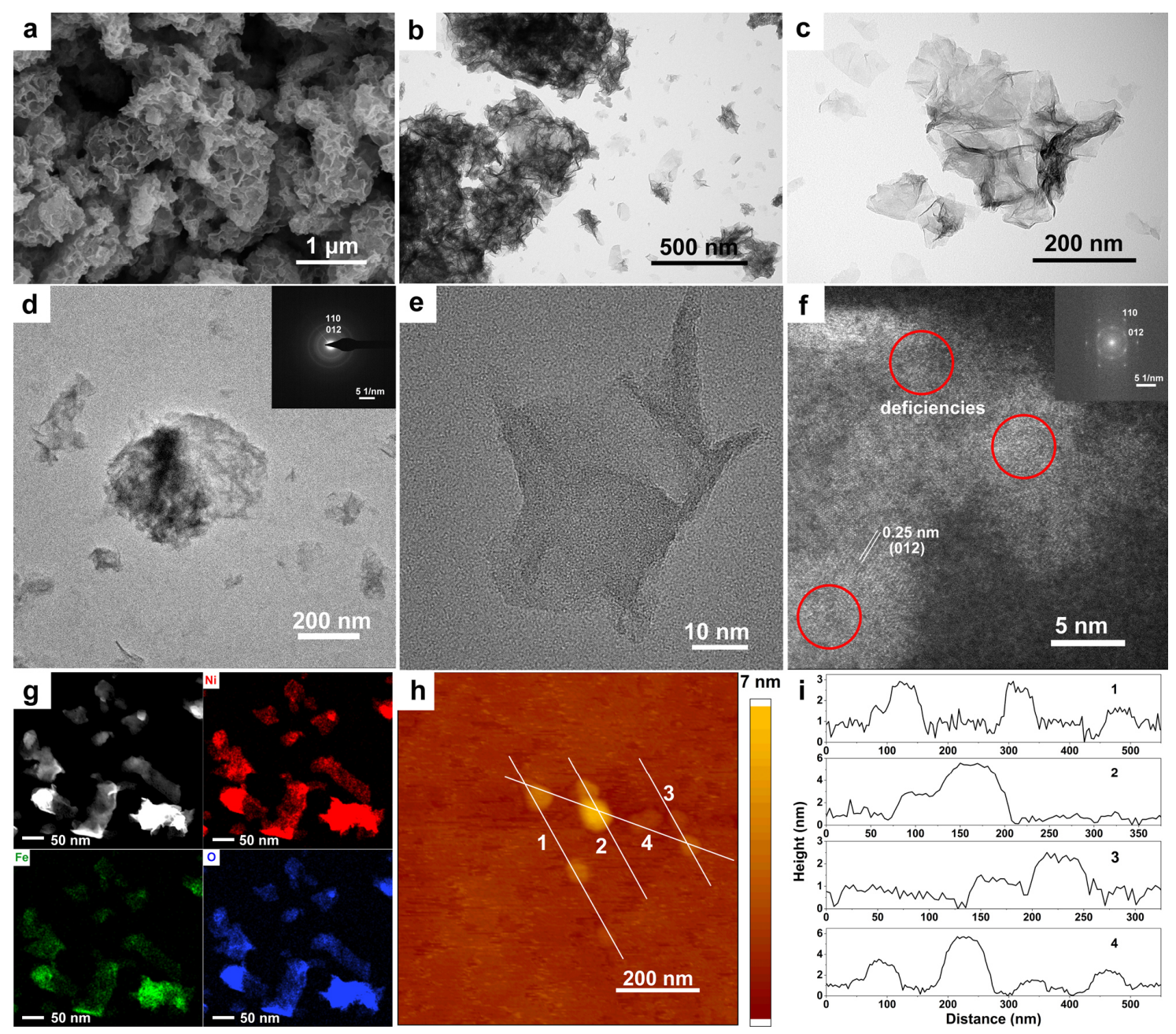

Figure 2. Characterization of $\mathrm{R}-\mathrm{Ni}_{10-\mathrm{x}} \mathrm{Fe}_{\mathrm{x}}$-CPs. (a-c) FESEM and TEM images of $\mathrm{R}-\mathrm{Ni}_{8} \mathrm{Fe}_{2}-\mathrm{CP}$ nanosheets (referred to in the following as representative R-NiFe-CP). (d, e) HR-TEM images of R-NiFe-CP nanosheets, the inset in (d) shows the corresponding SAED image. (f) HR-STEM and diffraction image (inset) of R-NiFe-CP nanosheets. (g) HAADF-STEM image and STEM-EDX elemental maps of R-NiFe-CP nanosheets. (h, i) AFM image and the corresponding height profiles of $\mathrm{R}-\mathrm{NiFe}-\mathrm{CP}$ nanosheets. 


\subsection{Preparation of low cyrstalline and ultra-thin $\mathrm{R}-\mathrm{Ni} \mathrm{i}_{10 \mathrm{x}} \mathrm{Fe}_{\mathrm{x}}-\mathrm{CP}$ nanosheets}

To prepare the low cyrstalline and ultra-thin $\mathrm{R}-\mathrm{Ni}_{10-\mathrm{x}} \mathrm{Fe}_{\mathrm{x}}-\mathrm{CP}$ nanosheets, $\mathrm{NaBH}_{4}$ was chosen as a reductant to produce structural deficiencies and distortions (see experimental details in the SI). ${ }^{[19,23,31-33]}$ The PXRD patterns (Figure S7) of $\mathrm{R}-\mathrm{Ni}_{10-\mathrm{x}} \mathrm{Fe}_{\mathrm{x}}-\mathrm{CPs}(0 \leq \mathrm{x} \leq 5)$ showed low crystallinity with main diffraction peaks at $2 \theta \approx 15.5^{\circ}$ and $26.8^{\circ}$, which correspond to the $(012)$ and (110) planes of a $\mathrm{Ni}(\mathrm{OH})_{2} \cdot 0.75 \mathrm{H}_{2} \mathrm{O}$ reference (JCPDS No. 38-0715), respectively. The broad diffraction peaks in the PXRD patterns indicate the strongly disordered nature of $\mathrm{R}-\mathrm{Ni}_{10}$ ${ }_{x} \mathrm{Fe}_{\mathrm{x}}-\mathrm{CPs}$. Additionally, the morphologies of the series of as-prepared $\mathrm{R}-\mathrm{Ni}_{10-\mathrm{x}} \mathrm{Fe}_{\mathrm{x}}-\mathrm{CP}$ nanosheets were characterized by FESEM and TEM. As shown in Figures 2a-c and Figures S8 and $\mathrm{S}$, the $\mathrm{R}-\mathrm{Ni}_{10-\mathrm{x}} \mathrm{Fe}_{\mathrm{x}}-\mathrm{CPs}$ can be described as ultra-thin nanosheets. The lack of well-defined diffraction rings for R-NiFe-CPs suggests their poor crystallinity, in line with the SAED pattern (inset in Figure 2d). Furthermore, a mixture of disordered and ordered domains, which further confirmed the lack of atomic lattice periodicity in the R-NiFe-CP nanosheets, was observed from HR-TEM and HR-STEM images (Figures 2e,f). The inset in the SAED pattern in Figure $2 \mathrm{f}$ suggests that the main exposed crystal planes in R-NiFe-CPs are the (012) and (110) planes. EDX elemental mappings (Figure 2g and Figure S10) displayed a uniform distribution of Ni, $\mathrm{Fe}$, and $\mathrm{O}$ on the surface of the nanosheets. Furthermore, the Ni/Fe atomic ratio was investigated by EDX and ICP-MS (Figure S11, Tables S5 and S6). The results showed that the atomic ratio of $\mathrm{Ni} / \mathrm{Fe}$ in $\mathrm{Ni}_{8} \mathrm{Fe}_{2}-\mathrm{CPs}$ differed significantly before (EDX 3.18:1, ICP-MS 3.21:1) and after the $\mathrm{NaBH}_{4}$ treatment (EDX 2.86:1, ICP-MS 2.96:1), suggesting that cation deficiencies were formed in the as-prepared ultra-thin nanosheets. More specifically, the formation of $\mathrm{Ni}$ deficiencies was facilitated compared to the Fe deficiencies (Table S6), and these cation deficiencies were compensated by oxygen deficiencies, as discussed below. The thickness of the as-synthesized ultra-thin $\mathrm{R}-\mathrm{NiFe}-\mathrm{CP}$ nanosheets was evaluated by atomic force microscopy (AFM, Figures $2 \mathrm{~h}-\mathrm{i}$ ). The heights of as-prepared ultra-thin nanosheet was measured across 
lines 1-4 from $0.8 \mathrm{~nm}$ to $1.8 \mathrm{~nm}$, corresponding to the monolayer and bilayer nanosheet morphologies of R-NiFe-CPs. Moreover, $\mathrm{Ni}_{8} \mathrm{Fe}_{2}-\mathrm{LDH}$ (referred to as $\mathrm{NiFe}-\mathrm{LDH}$ ) without structural deficiencies (Figures S12-14), rock salt-type NiFe-oxides derived from the NiFe-CPs (Figures S15-17), and NiFe-nanoparticles (NPs) with structural deficiencies (Figures S18-20) were compared as references. NiFe-LDH was prepared from a conventional urea-assisted method and showed a typical hexagonal nanoplate morphology. ${ }^{[34-37]}$ Rock salt-type NiFe-oxide was prepared by calcination of NiFe-CPs in air atmosphere. The FESEM and TEM images (Figure S16) show that the NiFe-oxides preserved the pristine nanosheet morphology quite well. When using $\mathrm{Ni} / \mathrm{Fe}$ ions as raw metal sources only, in the absence of CPs as precursor, randomly shaped nanoparticles were obtained, denoted as R-NiFe-NPs (see experimental details in the SI, Figures S18-20). The PXRD pattern (Figure S18) indicates that the R-NiFe-NPs display a phase mixture of metal hydroxides and metal alloys, which was mainly due to the fast reaction kinetics in the presence of high $\mathrm{NaBH}_{4}$ concentrations. ${ }^{[31-33,38]}$ All of the above results demonstrate that the controlled low-crystalline and ultra-thin (sub-2 nm) R-NiFe-CP nanosheets can selectively be fabricated by the herein applied CPs-assisted reduction strategy.

\subsection{XAS and XPS characterizations}

The local coordination environments of $\mathrm{Ni}$ and $\mathrm{Fe}$ atoms in the synthesized materials were characterized by XAS spectroscopy (Figures 3a-c and Figures S21 and S23-33). XAS data of Ni and Fe foils were fitted as standard references (Figures S21 and S24). Figure S23a depicts the Ni $K$-edge X-ray absorption near-edge structure (XANES) spectra of $\mathrm{Ni}_{10-\mathrm{x}} \mathrm{Fe}_{\mathrm{x}}-\mathrm{CPs}(\mathrm{x}=0,2$, and 5). The Ni $K$-edge XANES spectra of the $\mathrm{Ni}_{10-\mathrm{x}} \mathrm{Fe}_{\mathrm{x}}-\mathrm{CPs}$ show a characteristic pre-edge feature around $8335 \mathrm{eV}$ corresponding to the ideal square-planar geometry of $\mathrm{NiM}_{4}(\mathrm{M}$ : heteroatom). ${ }^{[39-42]}$ The Ni K-edge extended X-ray absorption fine structure (EXAFS) spectra were recorded to quantify the coordination environment of $\mathrm{Ni}$ atoms in $\mathrm{Ni}_{10-\mathrm{x}} \mathrm{Fe}_{\mathrm{x}}-\mathrm{CPs}$. The Fourier-transform FT-EXAFS spectrum of $\mathrm{Ni}_{5} \mathrm{Fe}_{5}$-CPs (Figure $\mathrm{S} 23 \mathrm{~b}$ ) displays two prominent 
peaks, one peak at $1.35 \AA$ associated to the Ni-C coordination shell, and another peak at 2.42 $\AA$ arising from the Ni-N coordination shell, which underscores the square-planar geometry of the $\mathrm{Ni}$ atoms in $\mathrm{Ni}_{5} \mathrm{Fe}_{5}-\mathrm{CPs}^{\left[{ }^{39-42]}\right.}$ The FT-EXAFS spectrum of Ni-CPs (Figure $\mathrm{S} 23 \mathrm{~b}$ ) shows three peaks in the range of $1-3 \AA$. The first one at $1.17 \AA$ corresponds to Ni-C/N pairs, the second one at $1.78 \AA$ arises from the $\mathrm{Ni}-\mathrm{O}$ bond, and the third one at $2.39 \AA$ is mainly due to the Ni-N/C pairs. ${ }^{[43,44]}$ Since the contributions of the Ni-C scattering path from the octahedral site and the Ni-N path from the square-planar site are quite similar (Figure S1a), the scattering of $\mathrm{Ni}-\mathrm{C} / \mathrm{N}$ or $\mathrm{Ni}-\mathrm{N} / \mathrm{C}$ pairs
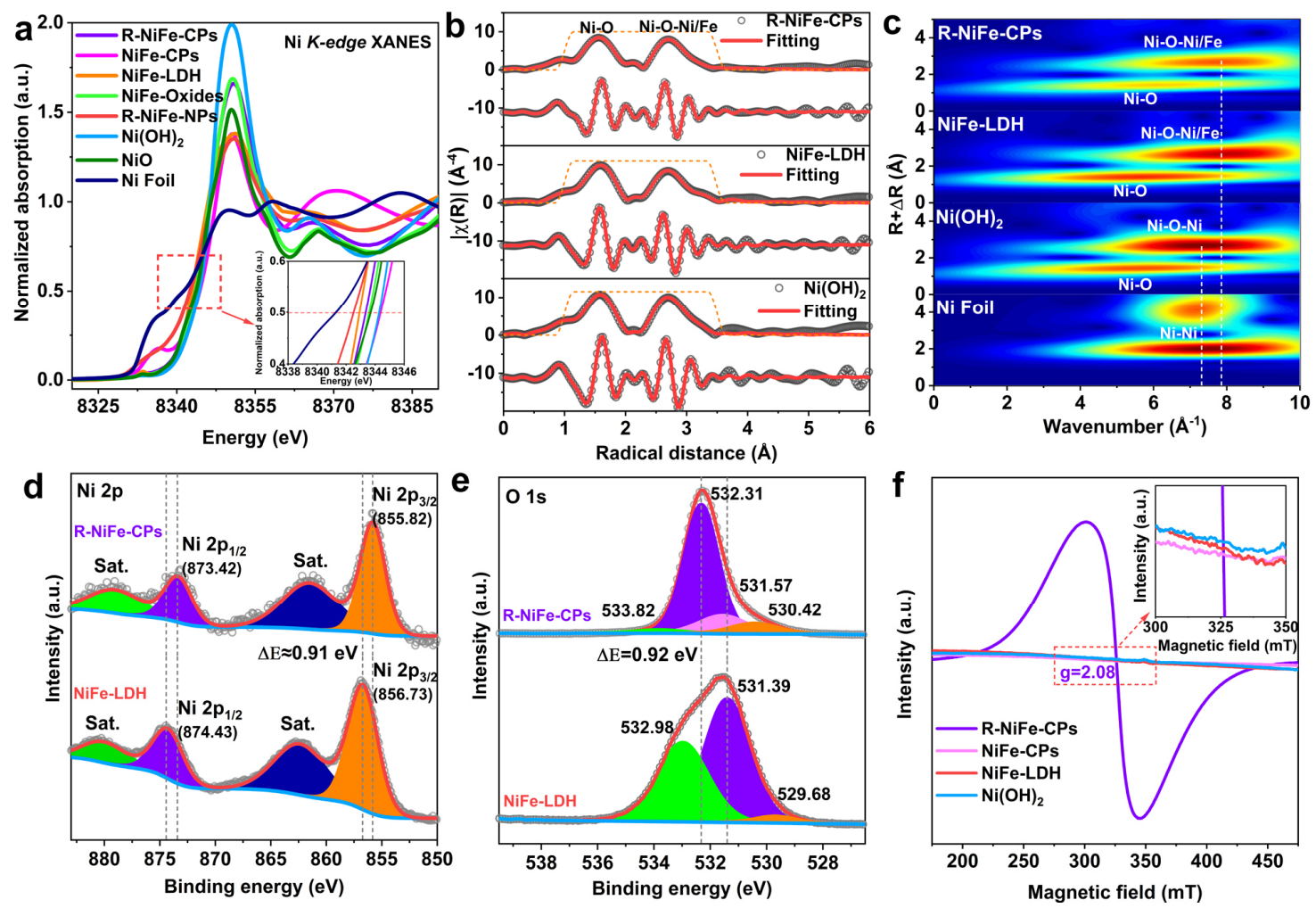

Figure 3. (a) Ni K-edge X-ray absorption near-edge structure (XANES) and zoom of the edge shifts (inset) of asprepared products vs. references. (b) Fitting of the Ni K-edge FT-EXAFS spectra of R-NiFe-CPs, NiFe-LDH, and reference $\mathrm{Ni}(\mathrm{OH})_{2}$. (c) Wavelet transformed (WT) contour plots of R-NiFe-CPs, NiFe-LDH, and $\mathrm{Ni}(\mathrm{OH})_{2}$ and $\mathrm{Ni}$ foil references. (d, e) High-resolution X-ray photoelectron spectroscopy (XPS) spectra of Ni 2p and O 1s for RNiFe-CPs and NiFe-LDH. (f) Room temperature EPR spectra for R-NiFe-CPs, NiFe-CPs, NiFe-LDH, and reference $\mathrm{Ni}(\mathrm{OH})_{2}$. 
cannot be distinguished for $\mathrm{Ni}_{10-\mathrm{x}} \mathrm{Fe}_{\mathrm{x}}-\mathrm{CPs}(\mathrm{x}=0$ and 2$) .{ }^{[45]}$ These results demonstrated that only the octahedral sites of the $\mathrm{Ni}$ atoms in $\mathrm{Ni}_{10-\mathrm{x}} \mathrm{Fe}_{\mathrm{x}}-\mathrm{CPs}$ were substituted by $\mathrm{Fe}$ atoms (Figure $\mathrm{S} 22$ ). The Fe $K$-edge XAS data (Figure $\mathrm{S} 25$ ) of $\mathrm{Ni}_{5} \mathrm{Fe}_{5}$-CPs showed a similar line shape and a slightly negative shift in comparison to that of $\mathrm{Ni}_{8} \mathrm{Fe}_{2}-\mathrm{CPs}$, suggesting that the local and electronic structures of $\mathrm{Fe}$ atoms in $\mathrm{Ni}_{10-\mathrm{x}} \mathrm{Fe}_{\mathrm{x}}-\mathrm{CPs}(\mathrm{x}=2$ and 5) remained more or less unchanged. Moreover, the rising-edge position was located between those of $\mathrm{FeO}$ and $\mathrm{Fe}_{2} \mathrm{O}_{3}$ reference oxides (Figure S25b), indicating that the Fe valence states followed the order $\mathrm{FeO}<\mathrm{Ni}_{8} \mathrm{Fe}_{2}-$ CPs $<\mathrm{Ni}_{5} \mathrm{Fe}_{5}-\mathrm{CPs}<\mathrm{Fe}_{2} \mathrm{O}_{3}$. A series of XAS measurements was then performed to access the local coordination environment of $\mathrm{Ni}$ and $\mathrm{Fe}$ atoms in $\mathrm{R}-\mathrm{Ni}_{10-\mathrm{x}} \mathrm{Fe}_{\mathrm{x}}-\mathrm{CPs}(\mathrm{x}=0,2$, and 5), NiFeLDH, NiFe-oxides, and R-NiFe-NPs (Figure 3a and Figures S26-33). The Ni K-edge XANES spectra of $\mathrm{R}^{-\mathrm{Ni}_{10-\mathrm{x}}} \mathrm{Fe}_{\mathrm{x}}-\mathrm{CPs}$, are analogous to those of $\mathrm{Ni}(\mathrm{OH})_{2}$ and $\mathrm{NiFe}-\mathrm{LDH}$ (Figure 3a and Figure 26a), further confirming that Ni-hydroxide related compounds were formed. The risingedge position of $\mathrm{R}-\mathrm{Ni}_{10-\mathrm{x}} \mathrm{Fe}_{\mathrm{x}}-\mathrm{CPs}$ is quite close to that of $\mathrm{Ni}(\mathrm{OH})_{2}$ and $\mathrm{NiFe}-\mathrm{LDH}$, indicating that the overall valence state of $\mathrm{Ni}$ centers in the $\mathrm{Ni}_{10-\mathrm{x}} \mathrm{Fe}_{\mathrm{x}}-\mathrm{CPs}$ is mainly $\mathrm{Ni}^{2+}$ (inset in Figure $3 a$ and Figure S26b). The Ni $K$-edge FT-EXAFS and EXAFS spectra of the different compounds are presented in Figure 3b, Figures S26c and S27. It was observed that the EXAFS oscillations for $\mathrm{R}-\mathrm{NiFe}-\mathrm{CPs}, \mathrm{NiFe}-\mathrm{LDH}$, and $\mathrm{Ni}(\mathrm{OH})_{2}$ are quite similar in the investigated $k$ space window from 2 to $10 \AA^{-1}$ (Figure S27), suggesting a similar local coordination environment of $\mathrm{Ni}$ atoms. The main coordination peak at $1.56 \AA$ (Figure $3 \mathrm{~b}$ ) corresponds to the Ni-O bonds, and the second coordination peak at $2.69 \AA$ is mainly due to scattering from the Ni-O-Ni/Fe bonds. ${ }^{[33,46-48]}$ However, while only one dominant peak arising from the Ni-O bonds was detected in R-Ni-CPs (Figure 26c), the scattering of the Ni-O-Ni/Fe bonds was not obvious when compared with that of $\mathrm{R}-\mathrm{Ni}_{10-\mathrm{x}} \mathrm{Fe}_{\mathrm{x}}-\mathrm{CPs}(\mathrm{x}=2$ and 5). These results suggest that the partial substitution of $\mathrm{Ni}$ by $\mathrm{Fe}$ atoms in $\mathrm{R}-\mathrm{Ni}_{10-\mathrm{x}} \mathrm{Fe}_{\mathrm{x}}-\mathrm{CPs}$ could form more stable bridging $\mathrm{Ni}-\mathrm{O}-\mathrm{Fe}$ bonds, which could regulate the electronic configuration of $\mathrm{Ni}_{10-\mathrm{x}} \mathrm{Fe}_{\mathrm{x}}-\mathrm{CPs}$ and promote their OER activity. Results from the fitting of FT-EXAFS spectra show that the coordination 
numbers $(\mathrm{CN})$ of metal centers in Ni-O and Ni-O-Ni bonds in $\mathrm{R}-\mathrm{Ni}_{10-\mathrm{x}} \mathrm{Fe}_{\mathrm{x}}-\mathrm{CPs}$ are smaller than those of NiFe-LDH and $\mathrm{Ni}(\mathrm{OH})_{2}$, while the $\mathrm{CN}$ of the Ni-O-Fe moieties does not significantly change (Figure 26d and Table S7). Combined with those results and the above analysis, we conclude that the as-prepared low-crystalline $\mathrm{R}-\mathrm{Ni}_{10-\mathrm{x}} \mathrm{Fe}_{\mathrm{x}}-\mathrm{CP}$ nanosheets contained rich structural deficiencies, and more specifically, that these deficiencies are mainly due to the absence of $\mathrm{O}$ and $\mathrm{Ni}$ atoms. Furthermore, the wavelet-transform (WT) contour plots (Figure 3c) were investigated and the relative magnitude of the $\mathrm{Ni}-\mathrm{O}$ and $\mathrm{Ni}-\mathrm{O}-\mathrm{Ni} / \mathrm{Fe}$ coordination shells was found to decrease in the order of R-NiFe-CPs $<\mathrm{NiFe}-\mathrm{LDH}$, indicating the presence of structural distortions with lower $\mathrm{CN}$ in R-NiFe-CPs. Besides, the Ni-O-Ni moiety of $\mathrm{Ni}(\mathrm{OH})_{2}$ was located at $\sim 7.34 \AA^{-1}$ with the most intense maximum, while NiFe-LDH and R-NiFe-CPs showed a positive shift to $\sim 7.85 \AA^{-1}$, which further supports the presence of bridging Ni-O-Fe bonds. ${ }^{[16]}$ The Fe $K$-edge data also provided analogous evidence for the presence of $\mathrm{O}$ and $\mathrm{Ni}$ deficiencies in R-NiFe-CPs (Figures S28 - S29 and Table S8), which was illustrated by the decreased $\mathrm{CN}$ of metal centers in Fe-O bonds and Fe-O-Ni moieties. For comparison, the electronic and local coordination environments of rock salt-type NiFe-oxides and R-NiFe-NPs were also explored (Figures S30-S33). The Ni $K$-edge XAS data of NiFe-oxides was similar to that of the reference $\mathrm{NiO}$, suggesting that the chemical state of $\mathrm{Ni}$ in both $\mathrm{NiFe}$-oxides and $\mathrm{NiO}$ was similar (Figure S30). The Fe K-edge XAS data of NiFe-oxides implied that the valence state of Fe was mainly +3 (Figure $29 \mathrm{~b}$ and Figure S31). The Ni $K$-edge and Fe $K$-edge XAS data (Figures S29b, S32, and S33) supported that the oxidation states of Ni and Fe in R-NiFeNPs were lower than in the $\mathrm{NiO}$ and $\mathrm{Fe}_{2} \mathrm{O}_{3}$ references, respectively, strongly indicating that Ni$\mathrm{Ni}$ (alloy) bonds were formed in R-NiFe-NPs.

Surface chemical compositions and oxidation states of the synthesized electrocatalysts were examined with X-ray photoelectron spectroscopy (XPS) spectroscopy (Figures 3d,e and Figures S34-37). As illustrated in Figure S35, the deconvoluted high-resolution XPS spectrum 
of $\mathrm{N} \mathrm{1s}$ in NiFe-CPs showed two peaks, one at $399.32 \mathrm{eV}$ and other one at $401.12 \mathrm{eV}$, which were assigned to N-C and N-Ni/Fe bonds. ${ }^{[39-41,49,50]}$ The deconvoluted high-resolution Ni $2 p$ XPS spectrum of NiFe-CPs displayed two pairs of peaks located at 856.72 and $872.42 \mathrm{eV}$, 858.32 and $875.62 \mathrm{eV}$, respectively, attributed to the Ni-O and Ni-C bonds. ${ }^{[45,51,52]} \mathrm{Fe}-\mathrm{O}$ bonds are evident from the high-resolution Fe $2 p$ spectrum shown in Figure S35c. Those results demonstrate the formation of $\mathrm{Ni} / \mathrm{Fe}\left(\mathrm{H}_{2} \mathrm{O}\right)-\mathrm{NC}-\mathrm{Ni}$ motifs in $\mathrm{NiFe}-\mathrm{CPs}$, where the $\mathrm{Ni}$ atoms at the octahedral sites are partially replaced by Fe atoms. The XPS spectra in Figures 3d,e and Figures S34-37 suggest the presence of Ni, Fe, and $\mathrm{O}$ in both NiFe-LDH and R-NiFe-CPs. Notably, no B signal was detected from the XPS B1s spectra of R-NiFe-CPs (Figure S36), which is further implying that $\mathrm{R}-\mathrm{NiFe}-\mathrm{CPs}$ emerged from the proposed reaction mechanism (see experimental details in the SI, Tables S2 and S4). ${ }^{[19,23]}$ Noteworthy, the binding energy of Ni $2 p$ in R-NiFe-CPs exhibited a negative shift around $0.91 \mathrm{eV}$ compared with that of NiFeLDH (Figure 3d). For the XPS spectrum of O $2 \mathrm{~s}$ in NiFe-LDH (Figure 3e), three main peaks located at 529.68, 531,39, and $532.98 \mathrm{eV}$, respectively, are assigned to metal-oxygen bonds, surface hydroxyl groups, and adsorbed water. ${ }^{[53-58]}$ However, the binding energies in the $\mathrm{O} 2 \mathrm{~s}$ XPS spectrum of R-NiFe-CPs are shifted slightly to higher values and a new peak located at $531.57 \mathrm{eV}$ appears, which can be assigned to oxygen deficiencies. ${ }^{[33,56-60]}$ The negative shift for $\mathrm{Ni}$ and $\mathrm{Fe} 2 \mathrm{p}$ and the positive shift for $\mathrm{O} 2 \mathrm{~s}$ is due to strong electronic interactions with electron transfer from anions to cations. ${ }^{[29,32,61]}$ Overall, the charge regulation by structural deficiencies and distortions in $\mathrm{R}-\mathrm{NiFe}-\mathrm{CPs}$ caused electron redistributions, which enhance the electron transfer properties and further improve the OER performance, as will be discussed in the following.

To obtain further evidence for structural deficiencies, electron paramagnetic resonance (EPR) spectra were recorded for R-NiFe-CPs, NiFe-CPs, and $\mathrm{NiFe}-\mathrm{LDH}$ as well as for $\mathrm{Ni}(\mathrm{OH})_{2}$ as a reference. As presented in Figure 3f, the R-NiFe-CPs exhibited a larger isotropic peak with a $g$ 
factor around 2.08, indicating the appearance of unpaired electrons arising from the structural deficiencies, ${ }^{[48,59,62]}$ which agrees with the XAS and XPS results. In contrast, no EPR signal was observed for $\mathrm{NiFe}-\mathrm{CPs}, \mathrm{NiFe}-\mathrm{LDH}$, and $\mathrm{Ni}(\mathrm{OH})_{2}$. Based on the above analytical results, we conclude that R-NiFe-CPs exhibit two different types of structural deficiencies (cation and anion deficiencies). Moreover, the insertion of $\mathrm{Ni}$ deficiencies was facilitated compared to $\mathrm{Fe}$ deficiencies (Figures S11, S26, S28 and Tables S5, S6). As reported, rational engineering of structural deficiencies can generate more active sites and promote fast electron transfer. ${ }^{[32,47,63,64]}$ This attractive strategy to enhance the OER properties of as-prepared electrocatalysts is applied in the following.
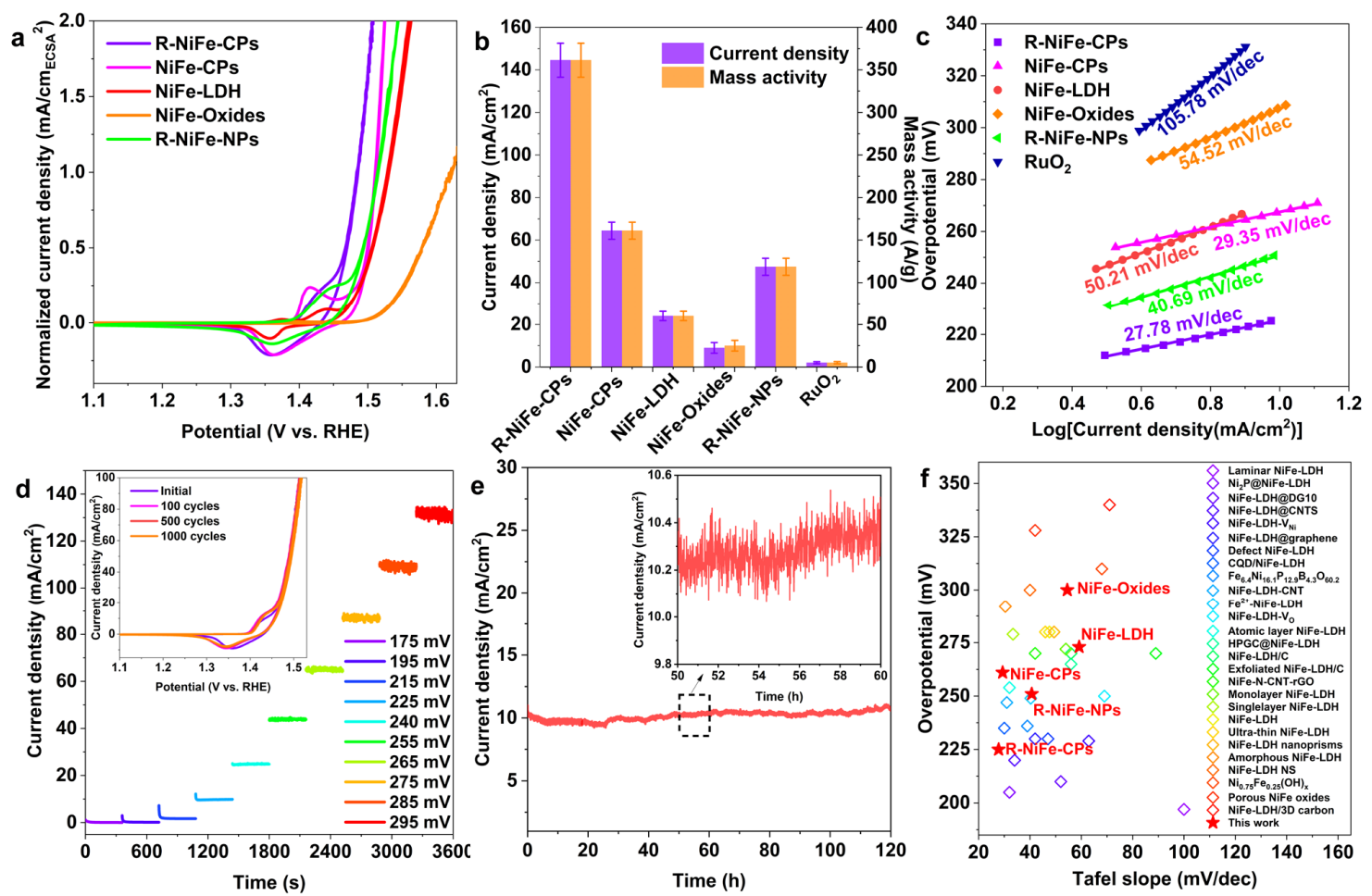

Figure 4. (a) CV curves (current normalized by ECSA) of as-prepared R-NiFe-CPs and NiFe-CPs, with NiFe-LDH, NiFeoxides, and R-NiFe-NPs as references. (b) Comparison of current densities based on geometric areas and mass activities at 1.53 V vs. RHE. (c) Tafel plots for the seven catalysts. (d) Multi-potential-step chronoamperometry of R-NiFe-CPs with an overpotential from 175 to $295 \mathrm{mV}$, the inset presents the potential cycling tests. (e) Stability measurements of R-NiFe-CPs loaded on Ni foam. (f) Summary of recent representative works of NiFe-based OER electrocatalysts with their corresponding overpotentials at a current density of $10 \mathrm{~mA} / \mathrm{cm}^{2}$ and Tafel slope values (Table S9). 


\subsection{Electrocatalytic OER performance}

The OER activities of as-prepared $\mathrm{Ni}_{10-\mathrm{x}} \mathrm{Fe}_{\mathrm{x}}-\mathrm{CPs}$ and $\mathrm{R}-\mathrm{Ni}_{10-\mathrm{x}} \mathrm{Fe}_{\mathrm{x}}-\mathrm{CPs}$ were evaluated with a standard 3-electrode system with Fe-free purified $1 \mathrm{M} \mathrm{KOH}$ (see experimental details in the SI). Ni-CPs and R-Ni-CPs were employed as reference catalysts here, because the substitution of Fe may either promote or diminish the OER activity, depending on the Fe content. ${ }^{[23,37,65-67]}$ Therefore, the effects of varying the $\mathrm{Ni} / \mathrm{Fe}$ atomic ratio on the OER performance were first investigated (Figure S38). A 90\% iR-correction was performed to evaluate all cyclic voltammetry (CV) measurements (Figure S39). As presented in Figure S38, the OER activities of the catalyst series exhibited a significant volcano trend as a function of the atomic ratio of $\mathrm{Ni} / \mathrm{Fe}$, which is consistent with previous studies on NiFe-based catalysts. ${ }^{[23,37,65-67]}$ The best OER performance was observed in the samples with $20 \% \mathrm{Fe}$ substitution, referred to herein as R-NiFe-CPs (see analytical section above). After optimizing the mass loading of as-prepared catalysts, the electrodes with $0.4 \mathrm{mg} / \mathrm{cm}^{2}$ exhibited the best OER activity (Figure S40).

To reflect the intrinsic activities of as-prepared catalysts, the current was normalized to the electrochemical surface area (ECSA) based on the plausible assumption that the catalytic OER process only involves the surface atoms. ${ }^{[5,68,69]}$ The ECSA values were determined by the calculation of the electrochemical double-layer capacitance (Figure S41-43). The overpotentials for attaining a current density of $10 \mathrm{~mA} / \mathrm{cm}_{\text {geometric }}{ }^{2}$ and specific current density of $1 \mathrm{~mA} / \mathrm{cm}_{\mathrm{ECSA}^{2}}{ }^{2}$ (Figure $4 \mathrm{a}$ and Figures S44) were used for activity comparison. ${ }^{[67,69,70]}$ The minimum overpotential value obtained for $\mathrm{NiFe}-\mathrm{LDH}$ was $273 \mathrm{mV}$ at $10 \mathrm{~mA} / \mathrm{cm}_{\text {geometric }}{ }^{2}$ and $299 \mathrm{mV}$ at $1 \mathrm{~mA} / \mathrm{cm}_{\mathrm{ECSA}}{ }^{2}$, which is consistent with previous studies. ${ }^{[47,57,67]}$ In particular, RNiFe-CPs displayed the highest OER activity (Figures S44b) with the lowest overpotential of $225 \mathrm{mV}$ at $10 \mathrm{~mA} / \mathrm{cm}_{\text {geometric }}{ }^{2}$ and $254 \mathrm{mV}$ at $1 \mathrm{~mA} / \mathrm{cm}_{\mathrm{ECSA}}{ }^{2}$, which is lower than that of NiFeCPs $(261 \mathrm{mV}$ and $281 \mathrm{mV}), \mathrm{NiFe}-$ oxides $(300 \mathrm{mV}$ and $395 \mathrm{mV})$, and R-NiFe-NPs $(251 \mathrm{mV}$ and $284 \mathrm{mV}$ ). Figure $4 \mathrm{~b}$ further summarizes the geometric current densities and specific mass 
activities of as-prepared catalysts and commercial $\mathrm{RuO}_{2}$ at an overpotential of $300 \mathrm{mV}$. As illustrated, R-NiFe-CPs display the highest geometric current density of $144.55 \mathrm{~mA} / \mathrm{cm}^{2}$ with a relatively high mass activity of $361.38 \mathrm{~A} / \mathrm{g}$ at an overpotential of $300 \mathrm{mV}$, which outperformed that of NiFe-CPs $\left(64.44 \mathrm{~mA} / \mathrm{cm}^{2}, 161.11 \mathrm{~A} / \mathrm{g}\right), \mathrm{NiFe}-\mathrm{LDH}\left(23.99 \mathrm{~mA} / \mathrm{cm}^{2}, 55.98\right.$ A/g), NiFe-oxides (8.99 mA/cm², $25.04 \mathrm{~A} / \mathrm{g}), \mathrm{R}-\mathrm{NiFe}-\mathrm{NPs}\left(47.47 \mathrm{~mA} / \mathrm{cm}^{2}, 118.68 \mathrm{~A} / \mathrm{g}\right)$, and commercial $\mathrm{RuO}_{2}\left(2.07 \mathrm{~mA} / \mathrm{cm}^{2}, 5.18 \mathrm{~A} / \mathrm{g}\right)$. These data demonstrate the good catalytic activity of the low-crystalline and ultra-thin R-NiFe-CP nanosheet catalysts.

To obtain further insight into the catalytic OER kinetics, the Tafel slope values were calculated for the as-prepared catalysts and commercial $\mathrm{RuO}_{2}$. As shown in Figure 4c, the R-NiFe-CPs exhibited the smallest Tafel slope value of $27.78 \mathrm{mV} / \mathrm{dec}$, which outperformed NiFe-CPs (29.35 $\mathrm{mV} / \mathrm{dec}), \mathrm{NiFe}-\mathrm{LDH}(50.21 \mathrm{mV} / \mathrm{dec}), \mathrm{NiFe}-$ oxides $(54.52 \mathrm{mV} / \mathrm{dec}), \mathrm{R}-\mathrm{NiFe}-\mathrm{NPs}$ (40.69 $\mathrm{mV} / \mathrm{dec})$, and commercial $\mathrm{RuO}_{2}(105.78 \mathrm{mV} / \mathrm{dec})$. The decreasing trend of Tafel slope values from R-NiFe-CPs to NiFe-LDH and subsequently to NiFe-oxides clearly shows the fast OER kinetics of the reductive materials. Furthermore, electrochemical impedance spectroscopy (EIS) characterizations were performed for the six catalysts (Figure S45). The EIS results clearly showed that R-NiFe-CPs displayed the smallest charge transfer resistance $\left(\mathrm{R}_{\mathrm{ct}}=9.41 \Omega\right)$, in line with the observed deficiencies and further results of the XAS/XPS data. Moreover, the distinct merits of ultra-thin morphologies can shorten electron/carrier diffusion length, facilitate mass transportation, and further promote the adsorption/desorption of OER intermediates, which all result in an improved OER activity. ${ }^{[14,19,47,71]}$

For the steady-state activity and stability measurements, a series of chronoamperometry experiments for the investigated catalysts were performed in purified $1 \mathrm{M} \mathrm{KOH}$ (Figures 4d, e and Figure S47). Figure $4 d$ presents the corresponding current density profiles within the overpotential range of $175 \mathrm{mV}$ to $295 \mathrm{mV}$. To achieve a current density of $10 \mathrm{~mA} / \mathrm{cm}_{\text {geometric }}{ }^{2}$, a minimum overpotential of $225 \mathrm{mV}$ was needed, which was maintained constant for $360 \mathrm{~s}$. 
Thereafter, the current density was increased, and durability was maintained, when the overpotential was applied from $240 \mathrm{mV}$ to $295 \mathrm{mV}$. Moreover, the rotating ring-disk electrode (RRDE) experiments exihibited a high Faradaic efficiency of nearly $96 \%$, confirming that the catalytic current densities indeed originated from the OER (Figure S46). ${ }^{[14,69]}$ The durability tests of as-prepared catalysts toward OER were performed at constant overpotential as shown in Figure S47. These results demonstrated that R-NiFe-CPs exhibit an impressive OER durability, which can hold up at an overpotential of $225 \mathrm{mV}$ for $10000 \mathrm{~s}$ without any obvious current drops. Moreover, the R-NiFe-CPs maintained near-identical CVs to the pristine curve after $1000 \mathrm{CV}$ cycles (inset in Figure 4d). As for the practical application potential, the catalyst was supported on $\mathrm{Ni}$ foam electrodes for extended long-time electrochemical durability measurements. We found that the real-time current density of R-NiFe-CPs showed only negligible changes after $120 \mathrm{~h}$ (Figure 4e), underscoring its robust stability. In addition, the OER activity of R-NiFe-CPs is comparable and the overpotential and Tafel slope value are substantially lower than that of most reported state-of-the-art NiFe-based and ultra-thin OER electrocatalysts (Figure $4 \mathrm{f}$ and Tables S9, S10)..$^{72-73}$

The post-electrocatalytic properties of the newly synthesized NiFe-CPs compared to R-NiFeCPs were further investigated by TEM and XAS spectroscopy (Figures S48 and S49). For NiFeCPs, both the Ni $K$-edge and Fe $K$-edge XANES spectra of the post-catalytic samples were different from those of their pristine counterparts (Figures S49a and S49c). Moreover, evaluations of the FT-EXAFS data (Figures S49b and S49d) revealed that all the corresponding peaks were similar to those of the reference oxide/hydroxides, indicating that the NiFe-CPs underwent a structural transformation during the OER, and that the in-situ formed oxide/hydroxides species served as the real active species. These observations are also consistent with recently reported studies on the underlying structural instability and phase transformation of transition metal-based CPs during OER. ${ }^{[13,42,74,75]}$ In contrast, the rising-edge 
of the XANES spectra for post-catalytic R-NiFe-CPs only showed a slight positive shift as compared to the pristine sample (Figure S50) while the basic pristine structure was maintained. This strongly suggests that the metal ions in the pristine samples were oxidized to high valence states, and these in-situ formed highly oxidized species can be regarded as the real active species for OER. ${ }^{[23,43,75,76]}$

\subsection{Computational analysis of structural deficiencies}
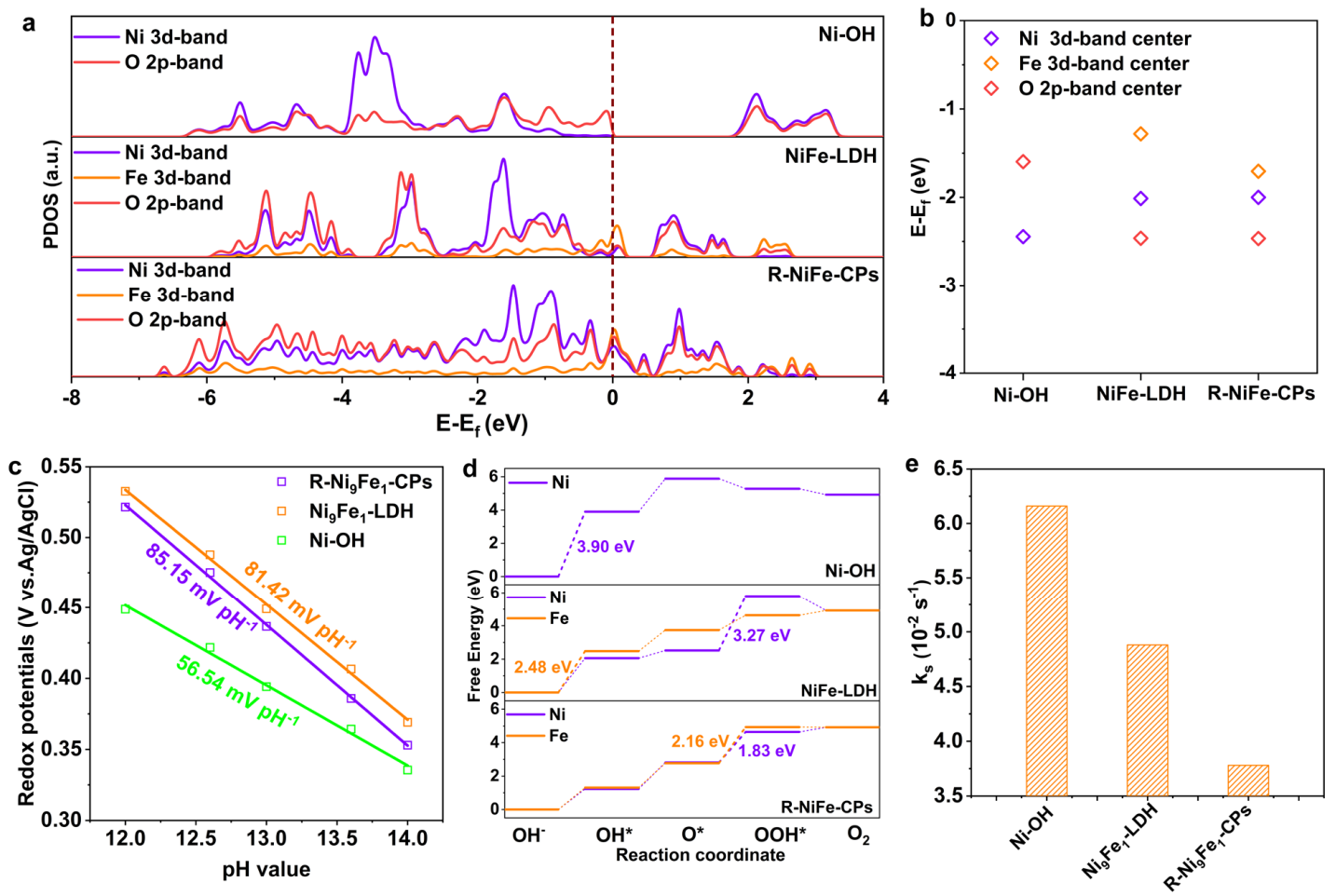

Figure 5. (a) Computed partial density of states (pDOS) of $\mathrm{Ni}-\mathrm{OH}, \mathrm{NiFe}-\mathrm{LDH}\left(\mathrm{Ni}_{8} \mathrm{Fe}_{2}\right)$, and $\mathrm{R}-\mathrm{NiFe}-\mathrm{CPs}\left(\mathrm{Ni}_{8} \mathrm{Fe}_{2}\right)$.

(b) Calculated Ni 3d, Fe 3d, and O 2p-band centers of three catalysts. (c) Pourbaix diagram of Ni-OH, NiFe-LDH, and R-NiFe-LDH, formal redox potentials vs. pH values. (d) Free energies of OER steps on Ni and Fe sites for the three catalysts at zero potential. (e) $\mathrm{k}_{\mathrm{s}}$ value of metal redox behaviors for $\mathrm{Ni}-\mathrm{OH}, \mathrm{Ni}_{9} \mathrm{Fe}_{1}-\mathrm{LDH}$, and $\mathrm{R}-\mathrm{Ni}_{9} \mathrm{Fe}_{1}-$ CPs.

To gain insight into the origins of catalytic performance in R-NiFe-CPs, DFT simulations were performed to fundamentally understand the correlations between the structural deficiencies and 
the OER activity. Calculations of the partial density of states (pDOS) and total DOS were performed on the (110) surfaces of the starting model structures of Ni hydroxide (refered to Ni$\mathrm{OH}$ ), NiFe-LDH, and R-NiFe-CPs (see DFT calculations in the SI, Figure 5a and Figures S5154). ${ }^{[47,48]}$ As shown in Figure 5a, the valence band is spread over a range around $6 \mathrm{eV}$ and the lowest conduction band position with a bandgap around $1.8 \mathrm{eV}$ is displayed in Ni-OH. Conversely, NiFe-LDH clearly shows an increased pDOS for the occupied states near the Fermi level and furthermore a very small bandgap of about $0.3 \mathrm{eV}$ compared to Ni-OH. The enhanced DOS could promote the charge transfer and facilitate the adsorption/desorption properties of intermediates on the metal centers, thereby reducing the energy barriers for OER. ${ }^{[48,53,62,68]}$ The low-crystalline and ultra-thin R-NiFe-CPs displayed a continuous enhancement of the pDOS above the Fermi level, suggesting that further enhancement of electron transfer properties can be accomplished by the insertion of structural deficiencies. This conclusion is consistent with EIS results in Figure S46, in which R-NiFe-CPs exhibited the smallest charge transfer resistance. The metal-oxygen covalency, which is determined by calculating the energy difference between the metal $3 \mathrm{~d}$ and $\mathrm{O} 2 \mathrm{p}$ band centers, has been widely used as intrinsic factor correlated to the OER performance. ${ }^{[2,19,68,77-79]}$ Compared to $\mathrm{Ni}-\mathrm{OH}$, the energy difference between $\mathrm{Ni} 3 \mathrm{~d}$ and $\mathrm{O}$ $2 p$ band centers of NiFe-LDH is clearly lower (Figure $5 b$ ), suggesting that enhanced Ni-O covalency was obtained in NiFe-LDH. For R-NiFe-CPs, a similar Ni-O covalency is observed, but an increased Fe-O covalency was found compared to NiFe-LDH. This demonstrated that the Fe-O covalency plays a vital role in R-NiFe-CPs. The enhanced metal-oxygen covalency, which results from synergistic effects between Fe insertion and structural deficiencies, can promote the electron mobility between the metal cations and intermediate anions (e.g., $\mathrm{O}^{2-}$ and $\mathrm{O}_{2}{ }^{2-}$ ), thereby improving the OER kinetic properties. ${ }^{[68,77-79]}$

Additionally, it was reported that the OER reaction mechanism would change from a PCET to a PT/ET pathway with increasing metal-oxygen covalency. Morever, catalysts based on PT/ET 
were suggested to provide much better OER activity than based on PCET. ${ }^{[65,68,69,79-81]}$ Therefore, $\mathrm{pH}$-dependent experiments for $\mathrm{Ni}_{9} \mathrm{Fe}_{1}-\mathrm{LDH}$ and $\mathrm{R}-\mathrm{Ni}_{9} \mathrm{Fe}_{1}-\mathrm{CPs}$, based on the fact that their electrocatalytic behavior is similar to $\mathrm{Ni}_{8} \mathrm{Fe}_{2}-\mathrm{LDH}$ and $\mathrm{R}-\mathrm{Ni}_{8} \mathrm{Fe}_{2}-\mathrm{CPs}$ (Figure S55), were carried out to examine possible OER reaction mechanism in this study. As shown in Figure 5c, it was apparent that the catalytic activities of all those three catalysts exhibited strong $\mathrm{pH}$ dependence. The $\mathrm{pH}$-induced shift of $\mathrm{Ni}-\mathrm{OH}$ was $56.54 \mathrm{mV} / \mathrm{pH}$ (near-Nernstian $59 \mathrm{mV} / \mathrm{pH}$ ), which was in line with a PCET reaction mechanism. In contrast to the Nernstian behavior as shown by Ni-OH, both NiFe-LDH and R-NiFe-CPs proceed via a super-Nernstian behavior with a $\mathrm{pH}$-induced shift of 81.42 and $85.15 \mathrm{mV} / \mathrm{pH}$, respectively, which is representative for the PT/ET pathway. ${ }^{[65,68,81,82]}$ When the PT/ET pathway is dominant in a catalyst, the proton abstraction is changed from on the sluggish single metal site to the bridging metal sites, which would considerably decrease the theoretical overpotential for overcoming the OER kinetic barriers. ${ }^{[65,68,81]}$

The Gibbs free energies of oxygen-containing intermediates $\left(\Delta \mathrm{G}_{\mathrm{M}^{*}}\right)$ were further calculated to analyze the intrinsic catalytic activity of R-NiFe-CPs. $\Delta \mathrm{G}_{\mathrm{M}^{*}}(\mathrm{M}=\mathrm{OH}, \mathrm{O}$, and $\mathrm{OOH})$ was calculated on the surface of Ni-OH (110), NiFe-LDH (110), and of the low-crystalline R-NiFeCPs (110). ${ }^{[47,48]}$ The free energy profiles at zero potential, equilibrium potential, and minimum potentials for which all steps become downhill are summarized in Figure 5d and Figures S5658. The computational results reveal that the rate-determining step (RDS) for Ni-OH is the formation of the $\mathrm{OH}^{*}$ intermediate, which results in an overpotential of $2.67 \mathrm{~V}$. When introducing $\mathrm{Fe}$ into the crystal structure, $\mathrm{NiFe}-\mathrm{LDH}$ is shown to be more favorable for the formation of $\mathrm{OH}^{*}$, and the $\mathrm{RDS}$ changes to form $\mathrm{OOH}^{*}$ and $\mathrm{OH}^{*}$ intermediates with overpotentials of $2.04 \mathrm{~V}$ and $1.25 \mathrm{~V}$ on $\mathrm{Ni}$ and $\mathrm{Fe}$ sites, respectively. In contrast, the overpotentials of deficiencies-rich R-NiFe-CPs are reduced to $0.60 \mathrm{~V}$ and $0.93 \mathrm{~V}$ on the Ni and Fe sites, and the RDS was mainly arising from the formation of the $\mathrm{OOH}^{*}$ intermediate. The 
above calculations indicate that the generation of $\mathrm{OH}^{*}$ and $\mathrm{OOH}^{*}$, which are related to the adsorption of $\mathrm{OH}^{-}$ions on the metal sites, are the energy barriers for $\mathrm{Ni}-\mathrm{OH}, \mathrm{NiFe}-\mathrm{LDH}$, and $\mathrm{R}-\mathrm{NiFe}-\mathrm{CPs}$.

Therefore, the adsorption of $\mathrm{OH}^{-}$ions at the metal sites was investigated based on the RandlesSevcik and Laviron equations (Figures S59-61). ${ }^{[65,81,83]} \mathrm{R}-\mathrm{Ni}_{9} \mathrm{Fe}_{1}-\mathrm{CPs}$ possessed the highest diffusion constant of $\left(\mathrm{D}=5.92 \times 10^{-7} \mathrm{~cm}^{2} / \mathrm{s}\right)$ compared to $\mathrm{Ni}_{9} \mathrm{Fe}_{1}-\mathrm{LDH}\left(\mathrm{D}=6.08 \times 10^{-8} \mathrm{~cm}^{2} / \mathrm{s}\right)$ and $\mathrm{Ni}-\mathrm{OH}\left(\mathrm{D}=1.23 \times 10^{-8} \mathrm{~cm}^{2} / \mathrm{s}\right)$. The higher $\mathrm{D}$ value reflects the stronger adsorption properties of $\mathrm{OH}^{-}$ions for $\mathrm{R}-\mathrm{NiFe}-\mathrm{CPs}$. These investigations are consistent with the $\Delta \mathrm{G}_{\mathrm{M}^{*}}$ calculations, where $\mathrm{R}-\mathrm{NiFe}-\mathrm{CPs}$ exhibit the smallest energy barrier of $\mathrm{OH}^{*}$ and $\mathrm{OOH}^{*}$ intermediates. Furthermore, the rate constant of metal center redox $\left(\mathrm{k}_{\mathrm{s}}\right)$, which is regarded as an effective approach to elucidate the underlying metal adsorption sites for the OER process, was determined by the Laviron method. ${ }^{[81,83]}$ The results (Figures S59-61) corroborated that the $\mathrm{k}_{\mathrm{s}}$ value of $\mathrm{R}-\mathrm{Ni}_{9} \mathrm{Fe}_{1}-\mathrm{CPs}\left(3.78 \times 10^{-2} \mathrm{~s}^{-1}\right)$ was smaller than that of $\mathrm{Ni}_{9} \mathrm{Fe}_{1}-\mathrm{LDH}\left(4.88 \times 10^{-2} \mathrm{~s}^{-1}\right)$ and of $\mathrm{Ni}-\mathrm{OH}\left(6.16 \times 10^{-2} \mathrm{~s}^{-1}\right)$. The relatively high $\mathrm{D}$ and low $\mathrm{k}_{\mathrm{s}}$ value of $\mathrm{R}-\mathrm{Ni}_{9} \mathrm{Fe}_{1}-\mathrm{CPs}$ indicated that the coupling of ions with single metal sites was slower than that of $\mathrm{Ni}_{9} \mathrm{Fe}_{1}-\mathrm{LDH}$ and $\mathrm{Ni}$ $\mathrm{OH}$, and the dominant adsorption sites for $\mathrm{OH}^{-}$ions were the bridging metal sites $(\mathrm{Ni}-\mathrm{O}-\mathrm{Fe}) .{ }^{[81]}$ Combining these diffusion studies and the above DFT simulations, we conclude that the incorporation of structural deficiencies in $\mathrm{NiFe}-\mathrm{CPs}$ can productively tune the electronic structure, enhance the metal-oxygen covalency, facilitate the adsorption of OER intermediates towards more active bridging metal sites (Ni-O-Fe), and thereby give rise to the observed high OER activity. 

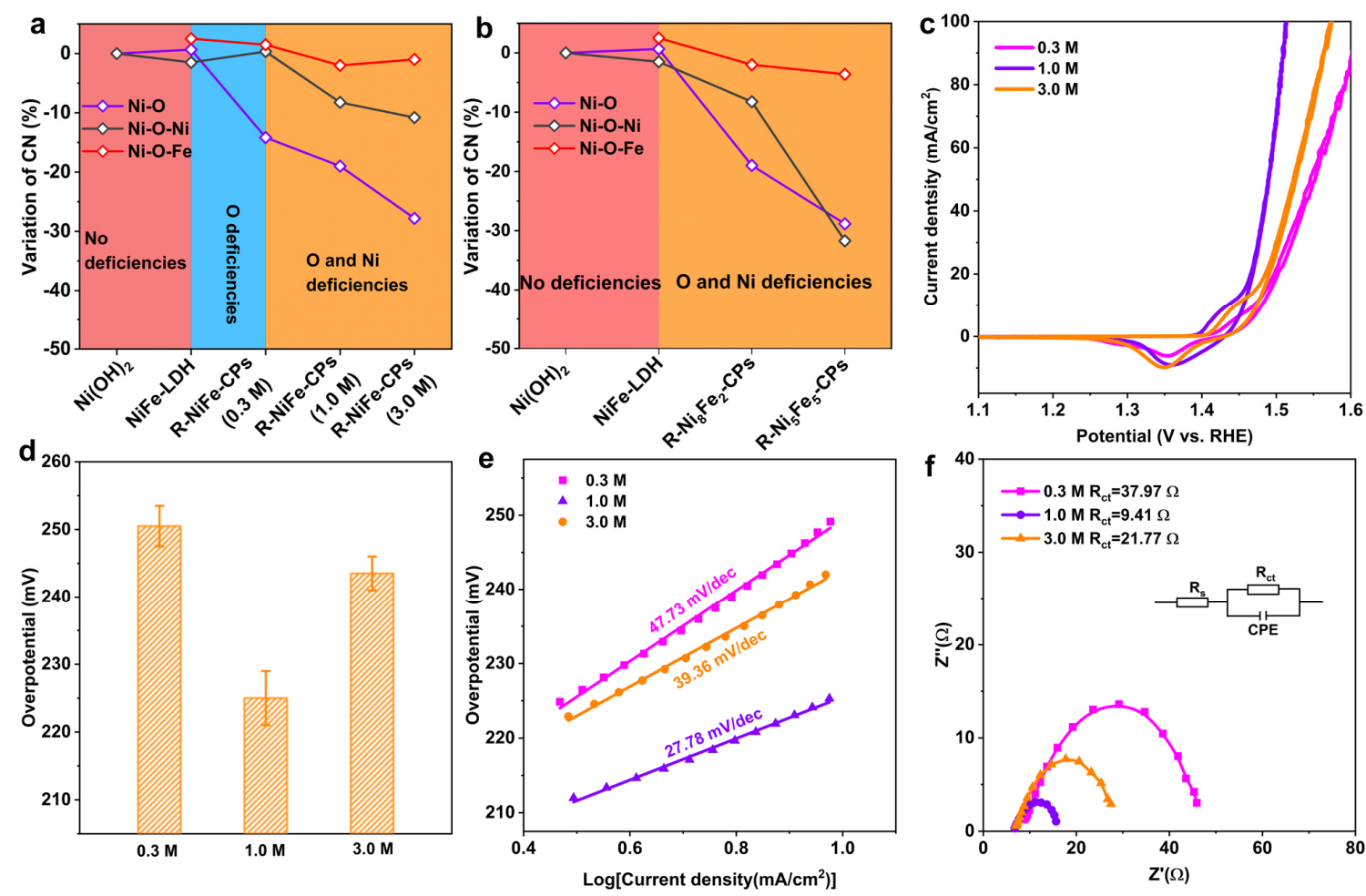

Figure 6. $(\mathrm{a}, \mathrm{b})$ Variation of $\mathrm{Ni}$ and Fe site coordination numbers $(\mathrm{CN})$ of the investigated samples. (c) CV curves of as-prepared R-NiFe-CPs with $0.3,1.0$, and $3.0 \mathrm{M}$ of $\mathrm{NaBH}_{4}$. (d) Comparison of current densities based on geometric areas at $1.53 \mathrm{~V}$ vs. RHE. (e) Tafel plots for the three catalysts. (f) Nyquist plots for the three catalysts.

\subsection{Modulation of the structural deficiencies}

According to the above experimental and computational investigations, the low-crystalline and ultra-thin R-NiFe-CPs present a good OER performance. We found that the presence of structural deficiencies played a vital role in the modulation of the electronic structure and OER performance of R-NiFe-CPs. Consequently, the modulation of structural deficiencies was further investigated by treating $\mathrm{NiFe}-\mathrm{CPs}$ with different concentrations of $\mathrm{NaBH}_{4}$. The asprepared catalysts were comprehensively characterized by PXRD, SEM, TEM, XAS, and EPR techniques (Figures S62-S68). From the EXAFS fitting results (Figures 6a,b and Figures S66, S67 and Tables S7, S8), it is observed that the R-NiFe-CPs ( $0.3 \mathrm{M})$ only show the absence of O atoms mainly around the Ni sites. The formation of Ni deficiencies was also observed when applying a high concentration of $\mathrm{NaBH}_{4}$ as demonstrated by the decreased $\mathrm{CN}$ of Ni-O-Ni and 
Fe-O-Ni shells. This phonemenon suggests that the $\mathrm{O}$ deficiencies were first formed, followed by the introduction of Ni deficiencies during the synthesis process. Moreover, the EPR signal intensities (Figure S68) showed an increasing trend as a function of the $\mathrm{NaBH}_{4}$ concentrations, implying that more structural deficiencies are formed in R-NiFe-CPs with a higher concentration of $\mathrm{NaBH}_{4}$. Next, the electrocatalytic OER performance was tested by employing R-NiFe-CPs obtained with different concentrations of $\mathrm{NaBH}_{4}(0.3,1.0$, and $3.0 \mathrm{M})$ as anodic materials. As shown in Figures 6c-f, the R-NiFe-CPs $(1.0 \mathrm{M})$ displayed the best OER performance with a low overpotential value of $225 \mathrm{mV}$ at $10 \mathrm{~mA} / \mathrm{cm}_{\text {geometric }}{ }^{2}$, a small Tafel value of $27.78 \mathrm{mV} / \mathrm{dec}$, and fast electron transfer. Upon further introduction of more $\mathrm{O}$ and $\mathrm{Ni}$ deficiencies, the R-NiFe-CPs (3.0 M) showed an inferior OER performance with a higher charge transfer resistance. This is mainly due to a strong relationship between $\Delta \mathrm{G}_{\mathrm{M}^{*}}$ and structural deficiencies (Figure 5d), where the energy barriers of different OER intermediates can be modulated by the structural deficiencies. ${ }^{[47,58,83]}$ Optimal catalysts should have neither too high nor too low adsorption or deprotonation energies, along the lines of Sabatier's principle. ${ }^{[53,84-}$ 86].

\section{Conclusions}

Low-crystalline and ultra-thin $\mathrm{R}-\mathrm{NiFe}-\mathrm{CP}$ nanosheets with tunable and high degrees of structural deficiencies were synthesized for the first time via a facile room-temperature reduction strategy. The optimized ultra-thin $\mathrm{R}-\mathrm{NiFe}-\mathrm{CP}$ nanosheets exhibit a superior OER performance with a very low overpotential of $225 \mathrm{mV}$ at a current density of $10 \mathrm{~mA} / \mathrm{cm}^{2}$ and robust electrochemical durability at extended long-time operation over $120 \mathrm{~h}$. They outperform commercial $\mathrm{RuO}_{2}$ and most of the NiFe-based state-art-of electrocatalysts reported to date.

This remarkable electrocatalytic performance of R-NiFe-CPs has mainly been achieved through

tuning the following factors: (1) The ultra-thin (sub-2 nm) layered morphologies enable 
enhanced access to active sites, fast electron transfer, and predominately exposed crystal facets.

(2) The partial substitution of $\mathrm{Ni}$ atoms by $\mathrm{Fe}$ generates Ni-O-Fe bridging metal sites with enhanced stability, thereby promoting a switch of $\mathrm{OH}^{-}$ion adsorption from the single metal sites to the Ni-O-Fe motifs. (3) Tuning of electronic structure, metal-oxygen covalency, and adsorption (deprotonation) energies of oxygen-intermediates through the incorporation of $\mathrm{O}$ and $\mathrm{Ni}$ deficiencies further enhances the electrocatalytic activity of R-NiFe-CPs. Investigations into the reaction mechanism revealed the presence of a PT/ET pathway in $\mathrm{R}-\mathrm{NiFe}-\mathrm{CPs}$ and showed that the RDS is mainly dependent on the adsorption of $\mathrm{OH}^{-}$at the dual bridging metal sites (Ni-O-Fe), which are identified as the catalytically active sites.

Due to their flexibility, convenience, and upscaling options in combination with the high performance, as achieved in the present study, coordination polymers emerge as highly promising materials to achieve higher surface areas with more exposed active metal sites through their layered structural properties. However, their current studies still face many challenges, especially with respect to productivity and efficiency. We demonstrate that the development of efficient and environmentally-friendly approaches in future works has high potential to generate reliable catalysts with large active surface areas and stable chemical structures during catalytic operation. This work paves the way to improve the rational design of CP-based electrocatalysts and opens up this vast compound class for low cost energy storage and conversion materials.

\section{Supporting Information}

Details on the synthesis, analytical characterizations, and electrocatalytic measurements can be found in the Supporting Information, together with additional XRD, SEM, EDX, EPR, ICPMS, XPS and XAS data as well as the electrochemical properties.

\section{Acknowledgments}

Y. G. Zhao and W. C. Wan contributed equally to this work. Y. G. Zhao, W. C. Wan, C. A. Triana, J. G. Li, C. K. Mavrokefalos, and G. R. Patzke thank the University of Zurich and the 
UZH Research Priority Program "Solar Light to Chemical Energy Conversion" (URPP LightChEC) for financial support. W. C. Wan thanks the China Scholarship Council (CSC) for his PhD fellowship. G. R. Patzke thanks the Swiss National Science Foundation (Sinergia Grant No. CRSII2_160801) for financial support. R. Erni acknowledges funding from the European Research Council (ERC) under EU's Horizon 2020 Research and Innovation Program (Grant agreement no. 681312). The authors acknowledge the assistance and support of the Center for Microscopy and Image Analysis (UZH) in performing scanning electron microscopy experiments. We thank Dr. Viviane Grange (UZH) for elemental analysis measurements. We are grateful to HZB-BESSY II for the allocation of synchrotron radiation beamline and Dr. Götz Schuck for providing assistance in using beamline KMC-2.

Received: ((will be filled in by the editorial staff))

Revised: ((will be filled in by the editorial staff))

\section{References}

Published online: ((will be filled in by the editorial staff))

[1] J. H. Montoya, L. C. Seitz, P. Chakthranont, A. Vojvodic, T. F. Jaramillo, J. K. Nørskov, Nat. Mater. 2017, 16, 70.

[2] R. Gao, H. Zhang, D. Yan, Nano Energy 2017, 31, 90.

[3] N.-T. Suen, S.-F. Hung, Q. Quan, N. Zhang, Y.-J. Xu, H. M. Chen, Chem. Soc. Rev. 2017, $46,337$.

[4] Z.-F. Huang, J. Wang, Y. Peng, C.-Y. Jung, A. Fisher, X. Wang, Adv. Energy Mater. 2017, 7,1700544

[5] T. Wu, S. Sun, J. Song, S. Xi, Y. Du, B. Chen, W. A. Sasangka, H. Liao, C. L. Gan, G. G. Scherer, L. Zeng, H. Wang, H. Li, A. Grimaud, Z. Xu, Nat. Catal. 2019, 2, 763.

[6] M. Witman, S. Ling, A. Gladysiak, K. C. Stylianou, B. Smit, B. Slater, M. Haranczyk, J. Phys. Chem. C 2017, 121, 1171.

[7] G. Yasin, L. Luo, W. Ye, M. A. Mushtaq, X. Fang, X. Xiang, S. Ji, D. Yan, Applied Catalysis B: Environ 2020, 265, 118559.

[8] T. Li, Y. Bai, Y. Wang, H. Xu, H. Jin, Coord. Chem. Rev. 2020, 410, 213221.

[9] X. F. Lu, B. Y. Xia, S.-Q. Zang, X. W. D. Lou, Angew. Chem. Int. Ed. 2020, 59, 4634; Angew. Chem. 2020, 132, 4662.

[10] Y. Li, L. Zhang, X. Xiang, D. Yan, F. Li, J. Mater. Chem. A, 2014, 2, 13250.

[11] W. Cheng, X. Zhao, H. Su, F. Tang, W. Che, H. Zhang, Q. Liu, Nat. Energy 2019, 4, 115. 
[12] T. Qiu, Z. Liang, W. Guo, H. Tabassum, S. Gao, R. Zou, ACS Energy Letters 2020, 5, 520.

[13] Z.-Y. Yu, Y. Duan, J.-D. Liu, Y. Chen, X.-K. Liu, W. Liu, T. Ma, Y. Li, X.-S. Zheng, T. Yao, M.-R. Gao, J.-F. Zhu, B.-J. Ye, S.-H. Yu, Nat. Commun. 2019, 10, 2799.

[14] S. Zhao, Y. Wang, J. Dong, C.-T. He, H. Yin, P. An, K. Zhao, X. Zhang, C. Gao, L. Zhang, J. Lv, J.Wang, J. Zhang, A. M. Khattak, N. A. Khan, Z. Wei, J. Zhang, S. Liu, H. Zhao, Z. Tang, Nat. Energy 2016, 1, 16184.

[15] S. Jin, ACS Energy Letters 2019, 4, 1443.

[16] W. Zhang, Y. Wang, H. Zheng, R. Li, Y. Tang, B. Li, C. Zhu, L. You, M.-R. Gao, Z. Liu, S.-H. Yu, K. Zhou, ACS Nano 2020, 14, 1971.

[17] J. Li, W. Huang, M. Wang, S. Xi, J. Meng, K. Zhao, J. Jin, W. Xu, Z. Wang, X. Liu, Q. Chen, ACS Energy Letters 2019, 4, 285.

[18] Y.-T. Liu, X.-D. Zhu, L. Pan, Small 2018, 14, 1803632.

[19] C. Zhang, Y. Huang, Y. Yu, J. Zhang, S. Zhuo, B. Zhang, Chem. Sci. 2017, 8, 2769.

[20] C. A. Triana, R. Moré, A. J. Bloomfield, P. V. Petrović, S. G. Ferrón, G. Stanley, S. D. Zarić, T. Fox, E. N. Brothers, S. W. Sheehan, P. T. Anastas, G. R. Patzke, Matter 2019 , $1,1354$.

[21] H. Huang, S. Zhou, C. Yu, H. Huang, J. Zhao, L. Dai, J. Qiu, Energy Environ. Sci. 2020, 13,545 .

[22] Z.-F. Huang, J. Song, K. Li, M. Tahir, Y.-T. Wang, L. Pan, L. Wang, X. Zhang, J.-J. Zou, J. Am. Chem. Soc. 2016, 138, 1359.

[23] H. Ren, X. Sun, C. Du, J. Zhao, D. Liu, W. Fang, S. Kumar, R. Chua, S. Meng, P. Kidkhunthod, L. Song, S. Li, S. Madhavi, Q. Yan, ACS Nano 2019, 13, 12969.

[24] S. Zhuo, Y. Shi, L. Liu, R. Li, Le Shi, D. H. Anjum, Y. Han, P. Wang, Nat. Commun. 2018, 9, 3132 .

[25] M. Hu, S. Ishihara, Y. Yamauchi, Angew. Chem. Int. Ed. 2013, 52, 1235; Angew. Chem. 2013, 125, 1273. 
[26] S. J. Hibble, A. M. Chippindale, A. H. Pohl, A. C. Hannon, Angew. Chem. Int. Ed. 2007, 46, 7116 ; Angew. Chem. 2007, 119, 7246.

[27] X. Zhao, B. Pattengale, D. Fan, Z. Zou, Y. Zhao, J. Du, J. Huang, C. Xu, ACS Energy Letters 2018, 3, 2520.

[28] L. Trotochaud, S. L. Young, J. K. Ranney, S. W. Boettcher, J. Am. Chem. Soc. 2014, 136, 6744.

[29] F.-L. Li, P. Wang, X. Huang, D. J. Young, H.-F. Wang, P. Braunstein, J.-P. Lang, Angew. Chem. Int. Ed. 2019, 58, 7051; Angew. Chem. 2019, 131, 7125.

[30] C. R. Marshall, S. A. Staudhammer, C. K. Brozek, Chem. Sci. 2019, 10, 9396.

[31] C.-W. Tung, Y.-Y. Hsu, Y.-P. Shen, Y. Zheng, T.-S. Chan, H.-S. Sheu, Y.-C. Cheng, H. M. Chen, Nat. Commun. 2015, 6, 8106.

[32] L. Zhuang, L. Ge, Y. Yang, M. Li, Y. Jia, X. Yao, Z. Zhu, Adv. Mater. 2017, 29, 1606793.

[33] D. Ji, L. Fan, L. Tao, Y. Sun, M. Li, G. Yang, T. Q. Tran, S. Ramakrishna, S. Guo, Angew. Chem. Int. Ed. 2019, 58, 13840; Angew. Chem. 2019, 131, 13978.

[34] Z. Lu, W. Xu, W. Zhu, Q. Yang, X. Lei, J. Liu, Y. Li, X. Sun, X. Duan, Chem. Commun. 2014, 50, 6479 .

[35] Y. Jia, L. Zhang, G. Gao, H. Chen, B. Wang, J. Zhou, M. T. Soo, M. Hong, X. Yan, G. Qian, J. Zou, X. Yao, Adv. Mater. 2017, 29, 1700017.

[36] L. Lv, Z. Yang, K. Chen, C. Wang, Y. Xiong, Adv. Energy Mater. 2019, 9, 1803358.

[37] W. Wan, S. Wei, J. Li, C. A. Triana, Y. Zhou, G. R. Patzke, J. Mater. Chem. A 2019, 7, 15145.

[38] R. Jamil, M. Sohail, N. Baig, M. S. Ansari, R. Ahmed, Sci. Rep. 2019, 9, 15273.

[39] W. Liu, L. Zhang, W. Yan, X. Liu, X. Yang, S. Miao, W. Wang, A. Wang, T. Zhang, Chem. Sci. 2016, 7, 5758 . 
[40] D. M. Koshy, S. Chen, D. U. Lee, M. B. Stevens, A. M. Abdellah, S. M. Dull, G. Chen, D. Nordlund, A. Gallo, C. Hahn, D. C. Higgins, Z. Bao, T. F. Jaramillo, Angew. Chem. Int. Ed. 2020, 59, 4043. Angew.Chem. 2020, 132, 4072.

[41] K. Yuan, D. Lützenkirchen-Hecht, L. Li, L. Shuai, Y. Li, R. Cao, M. Qiu, X. Zhuang, M. K. H. Leung, Y. Chen, S. Ullrich, J. Am. Chem. Soc. 2020, 142, 2404.

[42] T. Sun, S. Zhao, W. Chen, D. Zhai, J. Dong, Y. Wang, S. Zhang, A. Han, L. Gu, R. Yu, X. Wen, H. Ren, L. Xu, C. Chen, Q. Peng, D. Wang, Y. Li, PNAS 2018, 115, 12692.

[43] X. Su, Y. Wang, J. Zhou, S. Gu, J. Li, S. Zhang, J. Am. Chem. Soc. 2018, 140, 11286.

[44] H. Jin, X. Liu, S. Chen, A. Vasileff, L. Li, Y. Jiao, L. Song, Y. Zheng, S.-Z. Qiao, ACS Energy Letters 2019, 4, 805.

[45] J. Yin, Q. Fan, Y. Li, F. Cheng, P. Zhou, P. Xi, S. Sun, J. Am. Chem. Soc. 2016, 138, 14546.

[46] Z. Cai, D. Zhou, M. Wang, S.-M. Bak, Y. Wu, Z. Wu, Y. Tian, X. Xiong, Y. Li, W. Liu, S. Siahrostami, Y. Kuang, X.-Q. Yang, H. Duan, Z. Feng, H. Wang, X. Sun, Angew. Chem. Int. Ed. 2018, 57, 9392; Angew. Chem. 2018, 130, 9536.

[47] X. Zhang, Y. Zhao, Y. Zhao, R. Shi, G. I. N. Waterhouse, T. Zhang, Adv. Energy Mater. 2019, 9, 1900881.

[48] Q. He, Y. Wan, H. Jiang, Z. Pan, C. Wu, M. Wang, X. Wu, B. Ye, P. M. Ajayan, L. Song, ACS Energy Letters 2018, 3, 1373.

[49] J. Tang, J. Liu, C. Li, Y. Li, M. O. Tade, S. Dai, Y. Yamauchi, Angew. Chem. Int. Ed. 2015, 54, 588; Angew. Chem. 2015, 127, 598.

[50] H. Zhang, W. Zhou, T. Chen, B. Y. Guan, Z. Li, X. W. D. Lou, Energy Environ. Sci. 2018, $11,1980$.

[51] C. Lei, Y. Wang, Y. Hou, P. Liu, J. Yang, T. Zhang, X. Zhuang, M. Chen, B. Yang, L. Lei, C. Yuan, M. Qiu, X. Feng, Energy Environ. Sci. 2019, 12, 149.

[52] Z. Zou, T. Wang, X. Zhao, W.-J. Jiang, H. Pan, D. Gao, C. Xu, ACS Catal. 2019, 9, 7356. 
[53] R. Zhang, Y.-C. Zhang, L. Pan, G.-Q. Shen, N. Mahmood, Y.-H. Ma, Y. Shi, W. Jia, L. Wang, X. Zhang, W. Xu, J.-J. Zou, ACS Catal. 2018, 8, 3803.

[54] W. Xu, F. Lyu, Y. Bai, A. Gao, J. Feng, Z. Cai, Y. Yin, Nano Energy 2018, 43, 110.

[55] Y. Teng, X.-D. Wang, J.-F. Liao, W.-G. Li, H.-Y. Chen, Y.-J. Dong, D.-B. Kuang, Adv. Funct. Mater. 2018, 28, 1802463.

[56] T. Hou, Y. Xiao, P. Cui, Y. Huang, X. Tan, X. Zheng, Y. Zou, C. Liu, W. Zhu, S. Liang, L. Wang, Adv. Energy Mater. 2019, 9, 1902319.

[57] T. Tian, M. Zheng, J. Lin, X. Meng, Y. Ding, Chem. Commun. 2019, 55, 1044.

[58] Z.-F. Huang, J. Song, S. Dou, X. Li, J. Wang, X. Wang, Matter 2019, 1, 1494.

[59] T. Tian, H. Gao, X. Zhou, L. Zheng, J. Wu, K. Li, Y. Ding, ACS Energy Letters 2018, 3, 2150.

[60] Y. Zhu, L. Zhang, B. Zhao, H. Chen, X. Liu, R. Zhao, X. Wang, J. Liu, Y. Chen, M. Liu, Adv. Funct. Mater. 2019, 29, 1901783.

[61] X. F. Lu, Le Yu, X. W. Lou, Sci. Adv. 2019, 5, eav6009.

[62] M. Asnavandi, Y. Yin, Y. Li, C. Sun, C. Zhao, ACS Energy Letters 2018, 3, 1515.

[63] T. Ling, D.-Y. Yan, Y. Jiao, H. Wang, Y. Zheng, X. Zheng, J. Mao, X.-W. Du, Z. Hu, M. Jaroniec, S.-Z. Qiao, Nat. Commun. 2016, 7, 12876.

[64] L. Xu, Q. Jiang, Z. Xiao, X. Li, J. Huo, S. Wang, L. Dai, Angew. Chem. Int. Ed. 2016, 55, 5277; Angew. Chem. 2016, 128, 5363.

[65] M. Görlin, J. Ferreira de Araújo, H. Schmies, D. Bernsmeier, S. Dresp, M. Gliech, Z. Jusys, P. Chernev, R. Kraehnert, H. Dau, P. Strasser, J. Am. Chem. Soc. 2017, 139, 2070.

[66] T. Kou, S. Wang, J. L. Hauser, M. Chen, S. R. J. Oliver, Y. Ye, J. Guo, Y. Li, ACS Energy Letters 2019, 4, 622.

[67] W. Ye, X. Fang, X. Chen, D. Yan, Nanoscale 2018, 10, 19484.

[68] Y. Zhou, S. Sun, J. Song, S. Xi, B. Chen, Y. Du, A. C. Fisher, F. Cheng, X. Wang, H. Zhang, Z. J. Xu, Adv. Mater. 2018, 30, 1802912. 
[69] Z.-F. Huang, J. Song, Y. Du, S. Xi, S. Dou, J. M. V. Nsanzimana, C. Wang, Z. J. Xu, X. Wang, Nat. Energy 2019, 4, 329.

[70] Y. Shi, Y. Yu, Y. Liang, Y. Du, B. Zhang, Angew. Chem. Int. Ed. 2019, 58, 3769; Angew. Chem. 2019, 131, 3809.

[71] Y. Zhao, X. Zhang, X. Jia, G. I. N. Waterhouse, R. Shi, X. Zhang, F. Zhan, Y. Tao, L.-Z. Wu, C.-H. Tung, D. O'Hare, T. Zhang, Adv. Energy Mater. 2018, 8, 1703585.

[72] M. Arif, G. Yasin, M. Shakeel, M. A. Mushtaq, W. Ye, X. Fang, S. Ji, D. Yan, Mater. Chem. Front. 2019, 3, 520.

[73] W. Ye, Y. Yang, X. Fang, M. Arif, X. Chen, D. Yan, ACS Sustainable Chem. Eng. 2019, 7,18085 .

[74] Z. Guo, W. Ye, X. Fang, J. Wan, Y. Ye, Y. Dong, D. Cao, D. Yan, Inorg. Chem. Front., 2019, 6, 687.

[74] J. Zhou, Y. Wang, X. Su, S. Gu, R. Liu, Y. Huang, S. Yan, J. Li, S. Zhang, Energy Environ. Sci. 2019, 12, 739 .

[75] Y. Zhao, C. K. Mavrokefalos, P. Zhang, R. Erni, J. Li, C. A. Triana, G. R. Patzke, Chem. Mater. 2020, 32, 1371.

[76] S. Sun, Y. Sun, Y. Zhou, S. Xi, X. Ren, B. Huang, H. Liao, L. P. Wang, Y. Du, Z. J. Xu, Angew. Chem. Int. Ed. 2019, 58, 6042; Angew. Chem. 2019, 131, 6103.

[78] X.-T. Wang, T. Ouyang, L. Wang, J.-H. Zhong, Z.-Q. Liu, Angew. Chem. Int. Ed. 2020, 59, 6492; Angew. Chem. 2020, 132, 6554.

[79] J.Song, C. Wei, Z.-F. Huang, C. Liu, L. Zeng, X. Wang, Z. J. Xu, Chem. Soc. Rev. 2020, 49, 2196.

[80] W. T. Hong, K. A. Stoerzinger, Y.-L. Lee, L. Giordano, A. Grimaud, A. M. Johnson, J. Hwang, E. J. Crumlin, W. Yang, Y. Shao-Horn, Energy Environ. Sci. 2017, 10, 2190.

[81] J. Wang, L. Gan, W. Zhang, Y. Peng, H. Yu, Q. Yan, X. Xia, X. Wang, Sci. Adv. 2018, 4, eaap7970. 
[82] C. Yang, O. Fontaine, J.-M. Tarascon, A. Grimaud, Angew. Chem. Int. Ed. 2017, 56, 8652; Angew. Chem. 2017, 129, 8778.

[83] E. Laviron, J. Electroanal. Chem. 1979, 100, 263.

[84] Y.-C. Zhang, N. Afzal, L. Pan, X. Zhang, J.-J. Zou, Adv. Sci. 2019, 6, 1900053.

[85] X. Miao, L. Zhang, L. Wu, Z. Hu, L. Shi, S. Zhou, Nat. Commun. 2019, 10, 3809.

[86] R. Gao, D. Yan, Adv. Energy Mater. 2020, 10, 1900954. 


\section{Table of Contents}

We developed a highly efficient and robust oxygen-evolving electrocatalyst based on deficiency-rich and ultra-thin (sub $2 \mathrm{~nm}$ ) NiFe coordination polymer derivatives. Experimental and theoretical studies corroborated that the high activity and stability of the investigated catalysts arose from dual bridging metal sites (Ni-O-Fe) in the tailor-made defective layered matrix.

Keywords: electrocatalysis, nanosheets, disorder, coordination polymers, oxygen evolution reaction

Yonggui Zhao,* Wenchao Wan,* Yi Chen, Rolf Erni, C. A. Triana, Jingguo Li, Christos K. Mavrokefalos, Ying Zhou and Greta R. Patzke*

Understanding and optimizing ultra-thin coordination polymer derivatives with high oxygen evolution performance

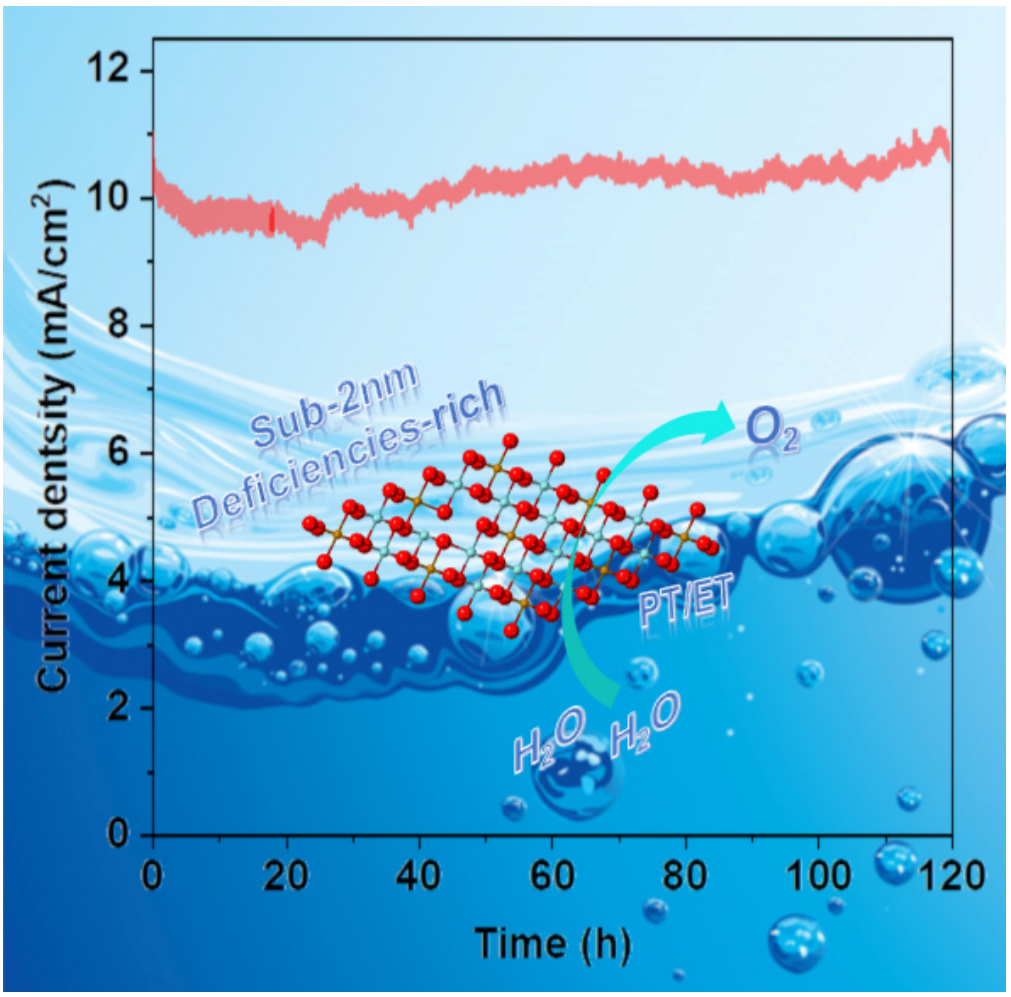

